\title{
The probable protective Effect of Quercetin Against Doxorubicin-Induced Hepatotoxicity in Adult Albino Rats: A Biochemical and Immunohistopathological Study
}

\author{
Sahar M. Moustafa ${ }^{1}$, Mona H. Ali², \\ ${ }^{1}$ Department of Forensic Medicine and Clinical Toxicology, Faculty of Medicine, Suez Canal University, Suez, Egypt. \\ ${ }^{2}$ Department of Anatomy, faculty of Medicine, Suez Canal University, Suez, Egypt.
}

\begin{abstract}
Background: Doxorubicin (DOX) is an anthracycline antineoplastic which causes hepatotoxicity by induction of free radicals and inflammatory liver tissues. Quercetin (QCT) is considered as a potent antioxidant that may ameliorates hepatotoxicity. Aim of the work: The current study was designed to detect the toxic effects of DOX in liver cells and evaluating the possible protective role of QCT against those toxic alterations in adult male albino rats. Materials and methods: forty (40) male albino rates were divided to four groups: Control (group I), DOX-treated (group II): Rats received $18 \mathrm{mg} / \mathrm{kg}$ of body weight of DOX. Group III, received $60 \mathrm{ml} / \mathrm{kg}$ of QCT combined with DOX. Group IV treated with DOX plus $100 \mathrm{ml}$ of QCT/kg. After scarification of rats, liver enzymes and the bile levels were estimated. The livers were extracted and used in oxidative stress markers, histological and immunological studies. Results: Doxorubicin administration induced an increase in liver enzymes, bile level and oxidative stress markers. QCT administration induced an improvement in those levels, especially with the high dose. The microscopic examinations of the DOX-treated sections showed loss of normal architectures of hepatic cells, enlargement and congestion of the central and portal veins and blood sinusoids, vacuolar degeneration, cholelithiasis and necrosis of H\&E stained hepatocytes. PAS-stained liver sections in the DOX-treated group showed an increase in the depth of the stain. Quercetin administration improved these changes and hepatocytes which stained with PAS showed moderate to mild staining, especially with the high dose of QCT. Sections of the stained liver caspase-3, in DOX-treated group showed positive results with intensity. QCT treated groups showed little effects of caspase-3, especially with the high dose. Conclusion: Doxorubicin had toxic effects on rats' livers, with significant improvement after treatment with QCT as an antioxidant substance, and its high doses were more protective than low doses.
\end{abstract}

Key words Doxorubicin, Quercetin, hepatotoxicity, albino rats

\section{Introduction}

$\mathrm{D}$ oxorubicin (DOX) is an anthracycline antineoplastic drug which used in treatment of many malignancies. Its significant dosedependent chronic toxicity as nephrotoxicity and hepatotoxicity led to its limited clinical usage (Beshay et al., 2011). Although the full mechanisms of DOXrelated toxicities are not completely understood yet DOX induces hepatotoxicity by induction of free radicals which generate oxidative damage besides its inflammatory changes in rates' hepatic tissues (Bulucu et al., 2009). Reactive oxygen species (ROS) may cause liver's membrane damage which induces liver enzymes release. DOX-induced toxic effects include increase in superoxide dismutase, catalase and glutathione peroxidase enzymes in liver tissue so, trying to control that oxidative injuries is highly appreciated (Alshabanah et al., 2010). Quercetin (QCT) is the most abundant polyphenolic flavonoid in nature, present in large amounts in vegetables and fruits as onions, broccoli, apples, grapes and green tea. It considered as a potent antioxidant as it has an antioxidant potential four times more than that of vitamin E (Dong et al., 2014). It was reported that QCT has many effects, including anti-allergy and antiinflammatory effects (Reutrakul et al., 2007). QCT can protect against drug-induced genotoxicity, hepatotoxicity, nephrotoxicity and oxidative stress in vivo (Qader et al., 2014). The antioxidant ability of QCT may be explained due to its high diffusion into cell membrane which permits it to sweep oxy radicals (Moskaug et al., 2004). QCT can ameliorate the hepatotoxic effect of diethylnitrosamine in rats by reducing aminotransferase (ALT) and aspartate aminotransferase (AST) serum levels and improves hepatic lipid peroxidation and hepatic glutathione (GSH) (Gupta et al., 2010) so, QCT may have a protective effect against DOX hepatotoxicity (Tiong et al., 2010).

\section{Aim of the Study}

The current study tried to detect the toxic effects of DOX on liver cells and evaluating the possible 
protective roles of QCT against those toxic alterations that might be induced in adult male albino rats.

\section{Materials and Methods}

The present study was conducted on forty healthy adult male albino rats (12-14 weeks) weighing 180-200 g. which maintained under controlled laboratory conditions of a 12-hours light and 12-hours dark cycle, at $25 \pm 2{ }^{\circ} \mathrm{C}$. All animals were provided with water and a standard pellet diet ad libitum. Prior to be utilized for experimental purpose, rats were left for two weeks allowing them to acclimatize to the new environment.

Experimental design: After the two weeks acclimatization period, the rats were divided randomly into four equal groups, each of ten rats as follows:

Group I (control group): Where rats were further subdivided into: Group Ia (negative control) where animals did not receive any treatment and Group Ib (positive control) where animals received a daily saline in a dose equivalent to that of DOX orally through gavage (Hiromasa et al., 2005 and Richter et al., 2007). Group II (DOX-treated group): Where rats received DOX in a dose of $6 \mathrm{mg} / \mathrm{kg}$ intra-peritoneal (I.P.) every week of the experiment (at days 1, 8, and 15 of the experiment) (Milic et al., 2009 and Ali et al., 2015).

Group III (DOX-treated plus QCT-treated low dose group): Where rats received an oral dose of QCT in a dose of $60 \mathrm{mg} / \mathrm{kg}$ body weight/day) combined with DOX in the same regimen as Group II (Richter et al., 2007 and Verma and Sangai, 2009).

Group IV (DOX-treated plus QCT-treated high dose group): where rats received an oral daily dose of QCT in a dose of $100 \mathrm{mg} / \mathrm{kg}$ body weight combined with DOX in the same regimen as Group II (El-Beshbishy et al., 2012). After 30 minutes of DOX injection, QCT was administered orally through gavage. All rats were weighed daily, and the doses of the drugs were adjusted accordingly as the experimental period lasted for 21 days. Drugs: Adricin vial containing $2 \mathrm{mg} / \mathrm{ml}$ of DOX was purchased from EIMC United Pharmaceuticals (Cairo, Egypt), and diluted with saline solution. DOX dose was equal to the lowest dose that is commonly used and resulting in serum levels close to those observed in human serum (Richter et al., 2007). An examination of data from sub-chronic and chronic toxicological studies support a dose of $18 \mathrm{mg} / \mathrm{kg}$ body weight as the used therapeutic dose of DOX is $60-75 \mathrm{mg} / \mathrm{m} 2$ IV once every 21 days. This dose is equivalent to $18-25 \mathrm{mg} / \mathrm{kg}$ in rats (Poole et al., 2015 and Hajra et al., 2018). QCT powder as pentahydroxy flavone (Q4951 Sigma) was dissolved in saline solution (Verma and Sangai, 2009). QCT dose was chosen on the basis of that it prevented daunorubicininduced elevation of plasma concentrations of lactate dehydrogenase and creatine kinase (Guzy et al., 2003)

Sample collection: At the time of sacrifice, the rats were anesthetized with ketamine $(80 \mathrm{mg} / \mathrm{kg}$ intraperitoneal). Body weight was measured before euthanization and livers were measured after euthanizing the animals and subjected for studies.

Biochemical study:

Measurement of liver function and hepatic necrosis markers:
Blood samples were collected from the retro-orbital venous plexus of all rats and centrifuged at $1500 \mathrm{rpm}$ for 10 minutes at room temperature and the serum was used for the estimation of total liver markers after separation. Aspartate aminotransferase (AST), alanine aminotransferase (ALT), alkaline phosphatase (ALP) and total bilirubin (TB) was determined by enzymatic colorimetric kits from Bio-diagnostic (Egypt) and reflotron plus machine by Roche, USA according to Reitman and Frankel (1957).

Estimation of oxidative stress markers and antioxidants:

Specimens of the liver tissue had washed by solution of ice-cold $0.9 \% \mathrm{NaCl}$ and homogenized in $9 \%$ ice-cold phosphate-buffered saline with $\mathrm{PH}$ 7.5. The homogenate had centrifuged at 3000 r.p.m for about 15 min. and the supernatant was collected and kept at $80^{\circ} \mathrm{C}$ (Fernadez-Botran et al., 2002). Hepatic level of malondialdehyde (MDA) as oxidative stress marker was measured according to Kei (1978) and glutathione (GSH) concentration as antioxidant marker was estimated according to Beutler et al (1963).

Histological study: Specimens of the liver tissues were fixed in $10 \%$ formalin, dehydrated and embedded in paraffin blocks then processed to prepare 4- $\mu \mathrm{m}$-thick for Haematoxylin and Eosin staining (Hx.\&E.) for studying the hepatic lobules architecture Periodic Acid Shiff staining (PAS) was used for studying glycogen contents (Bancroft and Gamble, 2002). Sections were studied using an image analyzer (Olympus Image J, NIH, 1.41b; Olympus, America Inc., Melville, New York, US (Lirdi et al., 2008).

Immunohistochemical study: Paraffin embedded blocks were further immunohistochemically analyzed using caspase-3 (Rat polyclonal Antibody, CPP32, Ab4, Thermo, UK) that purchased from LIFESPAN (BIOSCIENCE) for detection of caspse-3 cells markers in liver tissues.

Ethical considerations: After approval of Animal Ethics Committee to the experimental design, the experimental procedures and animal maintenance were conducted in accordance with the accepted standards of animal care. Animals were handled only by the investigator and maintained in manners that provide their physical comfort. There was no interference except after complete anesthesia and at the time of sacrifice. The rats were anesthetized with ketamine not with ether inhalation as it is forbidden now.

Statistical analysis: All values were presented as mean \pm SD. The differences among the groups with respect to all measured data parameters were statistically analyzed using one-way analysis of variance (ANOVA) and the post-hoc test using SSPS program, version 17 (IBM Corporation, Somers, New York, USA). The calculations were considered significant if $P$ value was less than 0.05 .

\section{Results}

The body and liver weight: Table (1) showed the rats body weights changes throughout the experiment in all groups. It showed non-significant decrease in all groups in comparison to control group. 
Table (2) showed the liver weight values in all groups, as DOX-treated group showed a high significant increase in liver weight compared to control group while the QCT treated group with low and high levels showed significant decrease compared to DOX-treated group and a significant increase compared to control group.

Biochemical results: Table (3) showed that serum level of ALT, AST, ALP and bilirubin are significantly increased in group II (DOX-treated) in a comparison with control group $(\mathrm{p}<0.05)$. The values showed a significant decrease in groups III and IV (QCT-treated) in comparison with group II (DOX-treated) and they remained significantly higher than their counterparts in control group $(\mathrm{p}<0.05)$.

Table (4) showed that MDA as an oxidative stress marker was significantly increased in group II (DOXtreated) in a comparison to control group $(\mathrm{p}<0.05)$, and significant decrease in groups III and IV (QCT-treated) in comparison to group II (DOX-treated). It remained significantly higher than their counterparts in control group $(p<0.05)$. The antioxidant marker $(G S H)$ level in DOX-treated group showed a high significant decrease in comparison to control group. The QCT treated groups showed significant increase in comparison to both DOX-treated and control groups.

Liver Histo-Pathological changes: H\&E stained sections of control group illustrated, the structural unit of the liver (hepatic lobule) formed of radiating cords of hepatic cells forming a network around the central vein and radiating to the lobular periphery (Figures 1 and 2). The hepatic cells appear cuboidal to polyhedral in shape with a centrally located nucleus. The hepatic cords are alternating with blood sinusoids, which lined with a discontinuous layer of flattened and fenestrated endothelial cells. The so-called portal triad consists of a portal venule, a hepatic arteriole and a bile ductule is illustrated in (Figures 3 and 4). Control group PAS stained sections showed faint positive PAS stained hepatocytes with scattered areas of glycogen precipitation (Figure 19). Examination of liver sections of H\&E stained hepatocytes in DOX-treated group II, revealed loss of normal architecture of hepatic lobules. Vascular changes such as dilatation and congestion of central and portal venules, hepatic arterioles and blood sinusoids, vacuolar degeneration of hepatocytes, cholestasis, and focal areas of necrosis, inflammatory infiltrations and hepatocytes nuclei showed pyknosis are illustrated in (Figures 5-11). DOX-treated group II showed high positive PAS stained hepatocytes with decreased glycogen contents (Figure 20). Examination of DOX-treated plus QCT-treated (low dose) group III sections which stained with H\&E, showed slight restoration of normal architecture of hepatic lobules and normal arrangement of hepatocytes in the centrilobular areas that were decreased and lost towards the periphery (Figures 12-14). DOX-treated plus QCT-treated (low dose) group III showed moderate positive PAS stained hepatocytes with moderate glycogen contents (Figure 21). In DOXtreated plus QCT-treated (high dose) group IV, H\&E stained hepatocytes, revealed intact and well defined cellular boundaries, few areas of vacuolar degeneration of hepatocytes. Slight congestion of central, portal and hepatic vessels and dilated congested blood sinusoids with slight inflammatory infiltrations were illustrated in (Figures 15-18). DOX-treated plus QCT-treated (high dose) group IV showed mild positive PAS stained hepatocytes with mild glycogen contents (Figure 22).

Immunological results: Caspase- 3 immunostaining showed a negative cytoplasmic Caspase-3 immunoexpression in control group I, a dense cytoplasmic Caspase-3 immuno-expression in DOX-treated group II. A few traces of brownish cytoplasmic Caspase-3 immuno-expression in DOX-treated plus QCT-treated (low dose) group III and a very few cytoplasmic Caspase-3 immuno-expression in DOX-treated plus QCT-treated (high dose) group IV illustrated in (Figures 23-26).

Table (1): Effect of Doxorubicin (DOX) and its combination with Quercetin (QCT) on body weight of rats using one-way ANOVA test

\begin{tabular}{|c|c|c|c|c|c|}
\hline \multirow{2}{*}{ Groups } & \multicolumn{5}{|c|}{ Body weight (gm) Mean \pm SD } \\
\cline { 2 - 6 } & In the first day & After one week & After two weeks & Day of scarification & P \\
\hline Group I & $196 \pm 5.5$ & $200 \pm 7.7$ & $201 \pm 5.6$ & $202 \pm 5.6$ & $195 \pm 3.4$ \\
\hline Group II & $197 \pm 5.6$ & $196 \pm 4.3$ & $196 \pm 1$ & $195 \pm 1$ & 0.107 \\
\hline Group III & $195 \pm 16$ & $195 \pm 4.4$ & $195 \pm 1.1$ & $196 \pm 4.9$ & 0.112 \\
\hline Group IV & $197 \pm 6$ & $197 \pm 3.3$ & $197 \pm 5.7$ & 5 \\
\hline
\end{tabular}

Each group consists of 10 rats, Group I: Control, Group II: DOX-treated group, Group III: DOX-treated plus QCTtreated $60 \mathrm{mg} / \mathrm{kg}$ body weight group, Group IV: DOX-treated plus QCT-treated $100 \mathrm{mg} / \mathrm{kg}$ body weight group, SD: Standard Deviation 
Table (2): Effect of Doxorubicin (DOX) and its combination with Quercetin (QCT) on liver weight of rats using one-way ANOVA test

\begin{tabular}{|c|c|c|}
\hline Groups & Liver weight $(\mathbf{g m})$ Mean \pm SD & P \\
\hline Group I & $7.5 \pm 0.14$ & $<0.05$ \\
\hline Group II & $13 \pm 0.56^{*^{\mathrm{a}}}$ & $<0.05$ \\
\hline Group III & $11.9 \pm 2.5^{\mathrm{a}, \mathrm{b}}$ & $<0.05$ \\
\hline Group IV & $10.7 \pm 2.6^{* \mathrm{a}, \mathrm{b}}$ & $<0.05$ \\
\hline
\end{tabular}

Each group consists of 10 rats, Group I: Control, Group II: DOX-treated group, Group III: DOX-treated plus QCTtreated $60 \mathrm{mg} / \mathrm{kg}$ body weight group, Group IV: DOX-treated plus QCT-treated $100 \mathrm{mg} / \mathrm{kg}$ body weight group, SD: Standard Deviation, * $P<0.05$ significant, a compared to control group, b compared to DOX-treated group.

Table (3): Effect of Doxorubicin (DOX) and its combination with Quercetin (QCT) on liver functions parameters of rats using one-way ANOVA test

\begin{tabular}{|c|c|c|c|c|c|}
\hline Parameters Mean \pm SD & Group I & Group II & Group III & Group IV & $\mathbf{P}$ \\
\hline $\operatorname{ALT}(\mathrm{U} / \mathrm{L})$ & $27.34 \pm 5.6$ & $133.6 \pm 6.9 *^{\mathrm{a}}$ & $75.8 \pm 4.7 *^{\mathrm{a}, \mathrm{b}}$ & $44.5 \pm 4.3 *$ *a,b,c & $<0.05$ \\
\hline AST (U/L) & $32.6 \pm 5.7$ & $127 \pm 5.7 *^{\mathrm{a}}$ & $67.8 \pm 4.3^{* \mathrm{a}, \mathrm{b}}$ & $40.22 \pm 6.3^{* a, b, c}$ & $<0.05$ \\
\hline $\operatorname{ALP}(\mathbf{U} / \mathbf{L})$ & $148.9 \pm 5.2$ & $194.7 \pm 10.45^{*^{\mathrm{a}}}$ & $166.76 \pm 12^{* \mathrm{a}, \mathrm{b}}$ & $158.96 \pm 10^{* a, b}$ & $<0.05$ \\
\hline Bilirubin (mg/dl) & $0.29 \pm 0.2$ & $0.80 \pm 0.06^{* a}$ & $0.39 \pm 0.05^{* \mathrm{a}, \mathrm{b}}$ & $0.33 \pm 0.03 * \mathrm{a}, \mathrm{b}$ & $<0.05$ \\
\hline
\end{tabular}

Each group consists of 10 rats, Group I: Control, Group II: DOX-treated group, Group III: DOX-treated plus QCTtreated $60 \mathrm{mg} / \mathrm{kg}$ body weight group, Group IV: DOX-treated plus QCT-treated $100 \mathrm{mg} / \mathrm{kg}$ body weight group, SD: Standard Deviation, * $P \leq 0.05$ significant, a compared to control group, b compared to DOX-treated group, c compared to DOX+QCT-treated group (60mg/kg body weight group).

Table (4): Effect of Doxorubicin (DOX) and its combination with Quercetin (QCT) on liver oxidative markers of rats using one-way ANOVA test

\begin{tabular}{|c|c|c|c|c|c|}
\hline Parameters Mean \pm SD & Group I & Group II & Group III & Group IV & P \\
\hline MDA (mmol/g tissue) & $47.17 \pm 4.1$ & $83.16 \pm 4.38^{* a}$ & $58.66 \pm 4.96^{* a, b}$ & $50.23 \pm 3.2 * a, b$ & $<0.05$ \\
\hline GSH (mmol/g tissue) & $6.29 \pm 0.2$ & $4.26 \pm 0.3^{* a}$ & $5.62 \pm 0.32^{* a, b}$ & $6.36 \pm 0.37 * a, b$ & $<0.05$ \\
\hline
\end{tabular}

Each group consists of 10 rats, MDA: Malondialdehyde, GSH: Glutathione, Group I: Control, Group II: DOX-treated group, Group III: DOX-treated plus QCT-treated $60 \mathrm{mg} / \mathrm{kg}$ body weight group, Group IV: DOX-treated plus QCTtreated $100 \mathrm{mg} / \mathrm{kg}$ body weight group, SD: Standard Deviation, * $P \leq 0.05$ significant, a compared to control group, b compared to DOX-treated group.

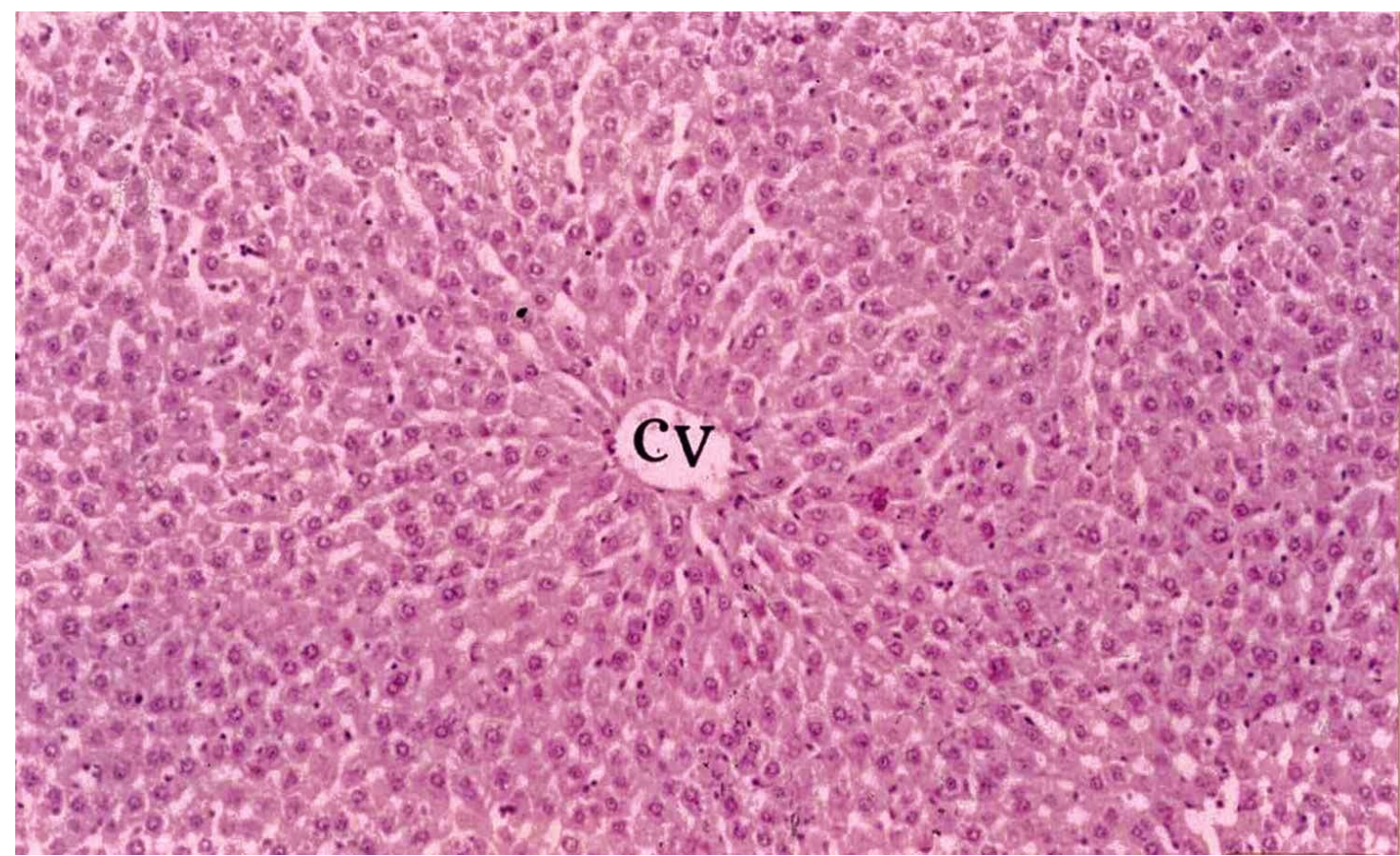

Figure (1): A photomicrograph of liver section in (control group I) showing normal architectural appearance of the hepatic lobules as they arranged in cords radiating from the central vein

(CV) (H\&E X 100) 


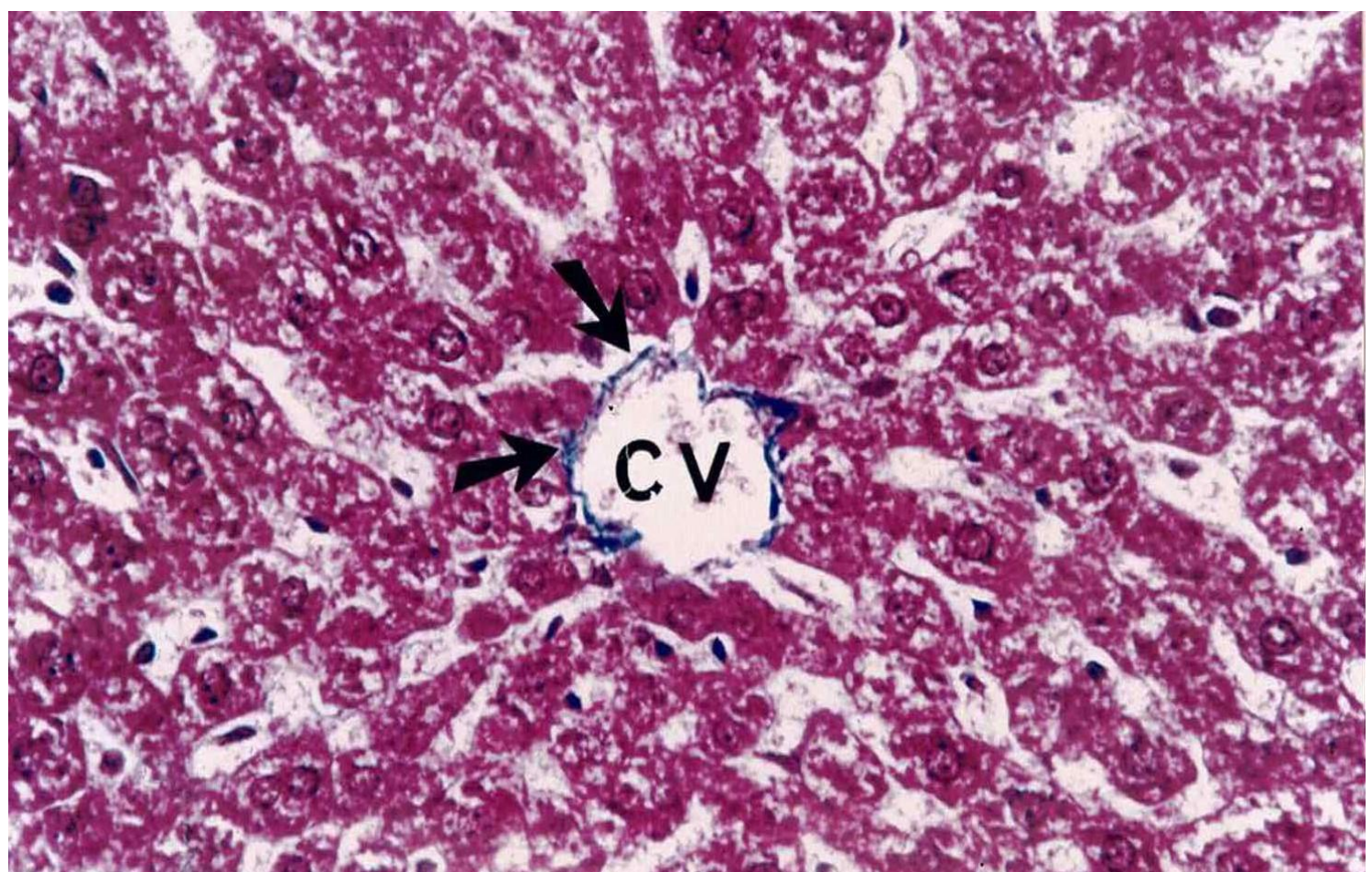

Figure (2): A photomicrograph of liver section in (control group I) showing normal connective tissue (arrows) surrounding the central vein $(\mathrm{CV})$ which observed as a thin layer of collagenous fibers (H\&E X 200)

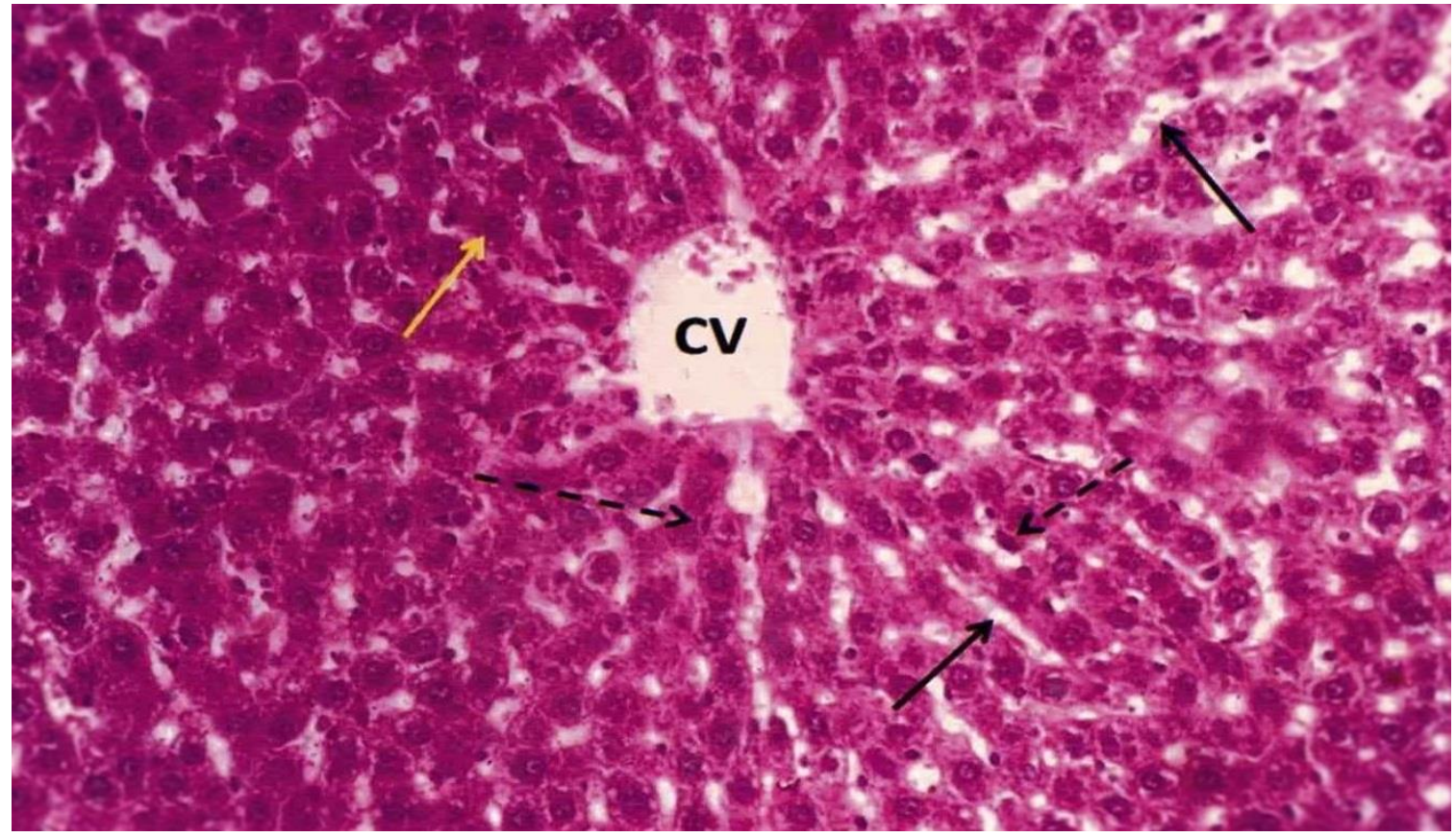

Figure (3): A photomicrograph of liver section in (control group I) showing normal architecture of hepatic lobule formed of hepatocytes (yellow arrow) which arranged in single-cell thick plates radiating around the central vein $(\mathrm{CV})$. These plates are separated by vascular sinusoids (black arrow) that lined by flat kuppfer cells (dashed arrow) (H\&E X 200) 


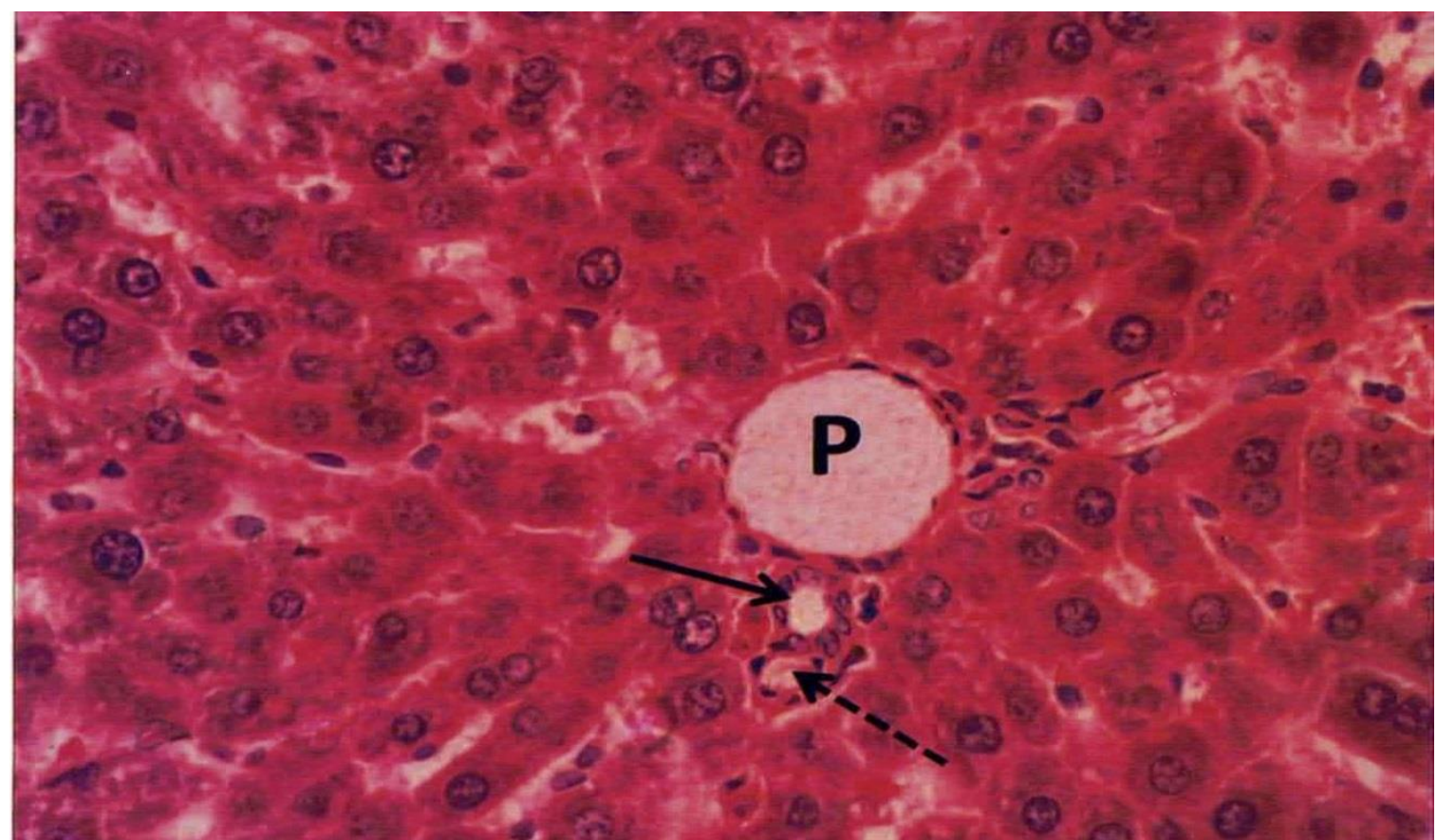

Figure (4): A photomicrograph of liver section in control group showing normal portal triad formed of portal venule (P), bile ductule (arrow) and hepatic arteriole (dashed arrow) (H\&E X400)

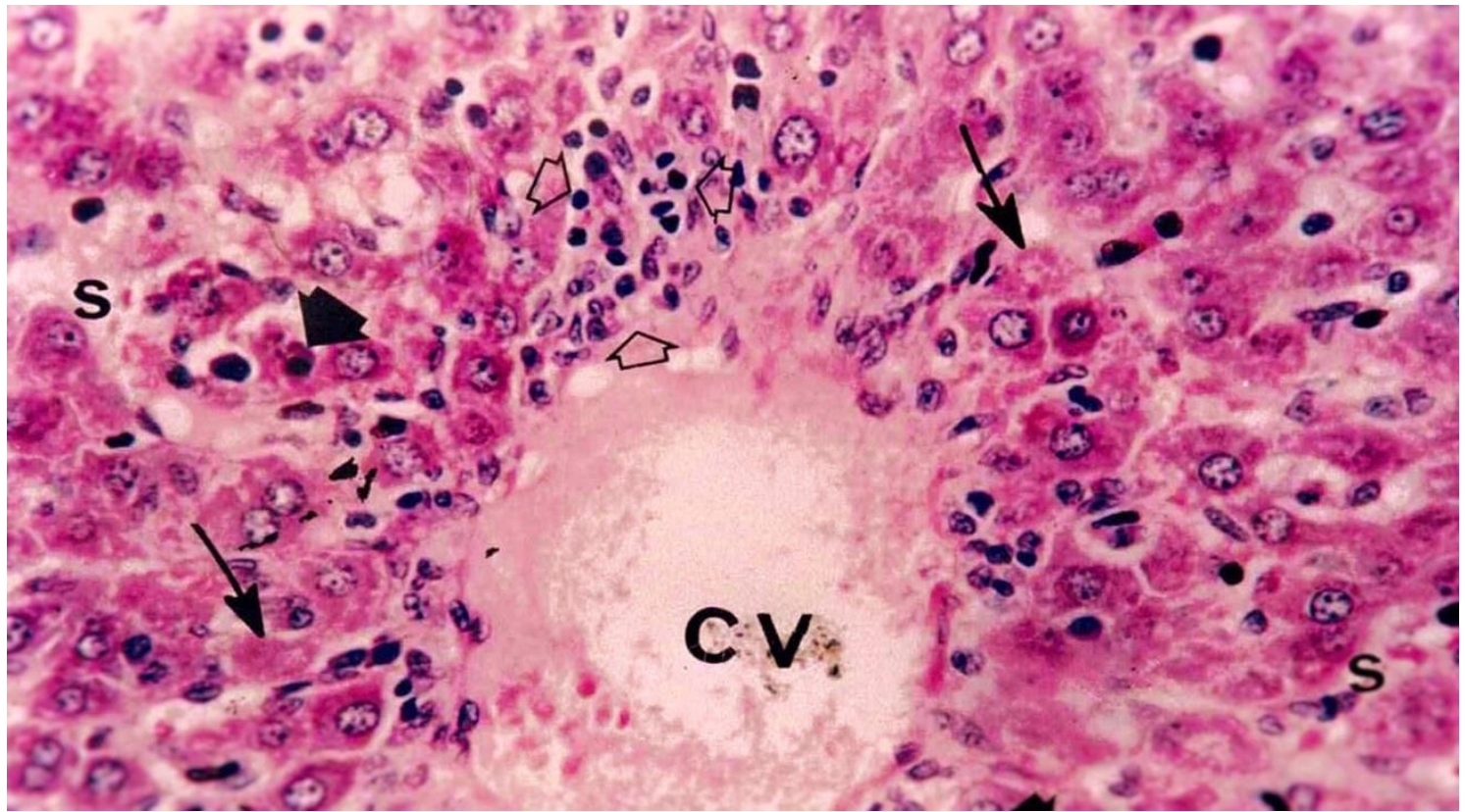

Figure (5): A photomicrograph of liver section in (DOX-treated group II) showing dilatation and congestion of the central vein $(\mathrm{CV})$ resulting in distortion of the normal hepatic lobular architecture with dilatation and congestion of the sinusoids (S) and some centrilobular hepatocytes showed pyknotic or absent nuclei (thin arrows). (H\&E X 200) 


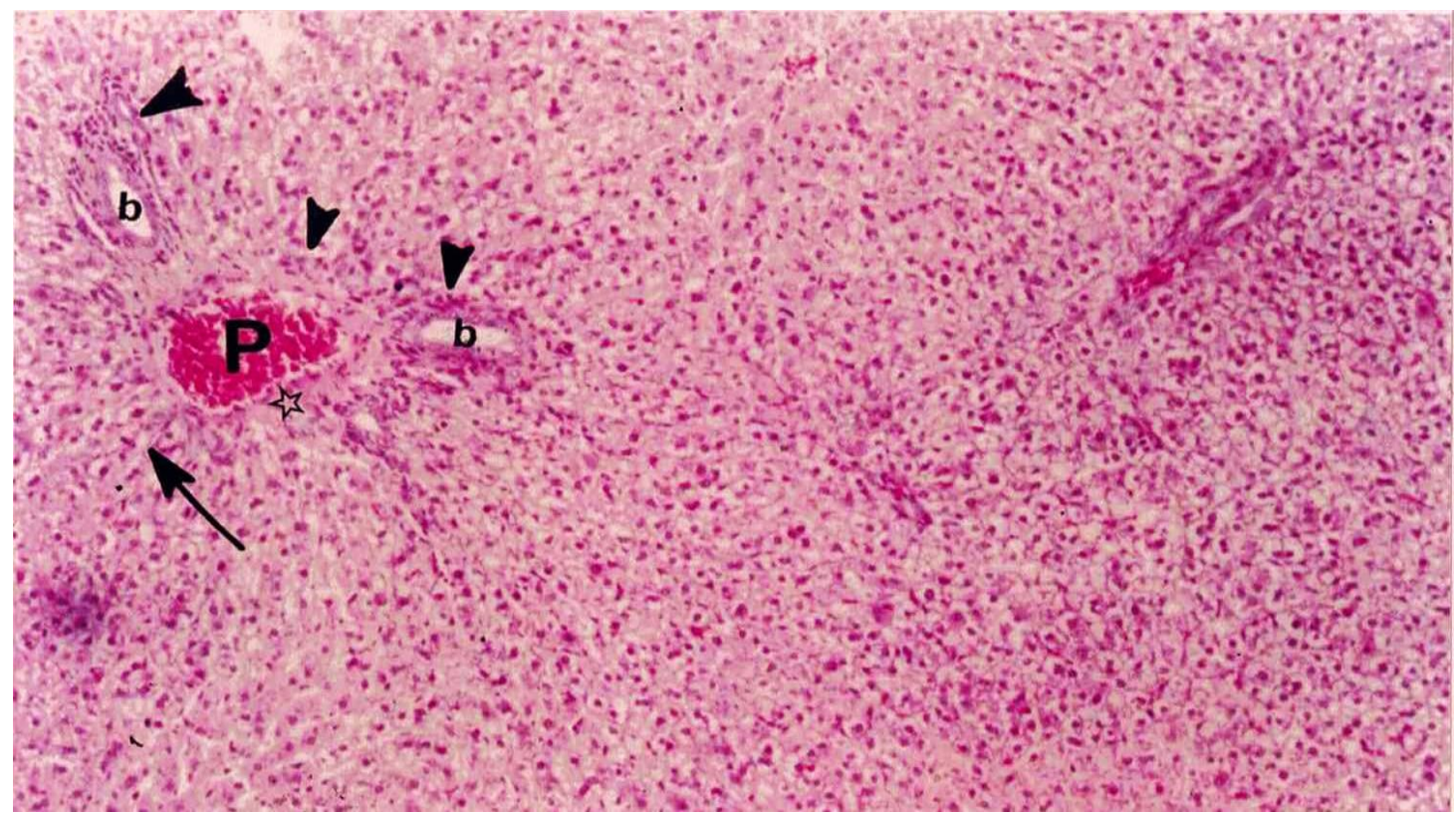

Figure (6): A photomicrograph of liver section in (DOX-treated group II) showing branches of the portal vein (arrow) with dilated bile ducts (b) (head arrows) which frequently encountered in the portal tract (P) (H\&E X200)

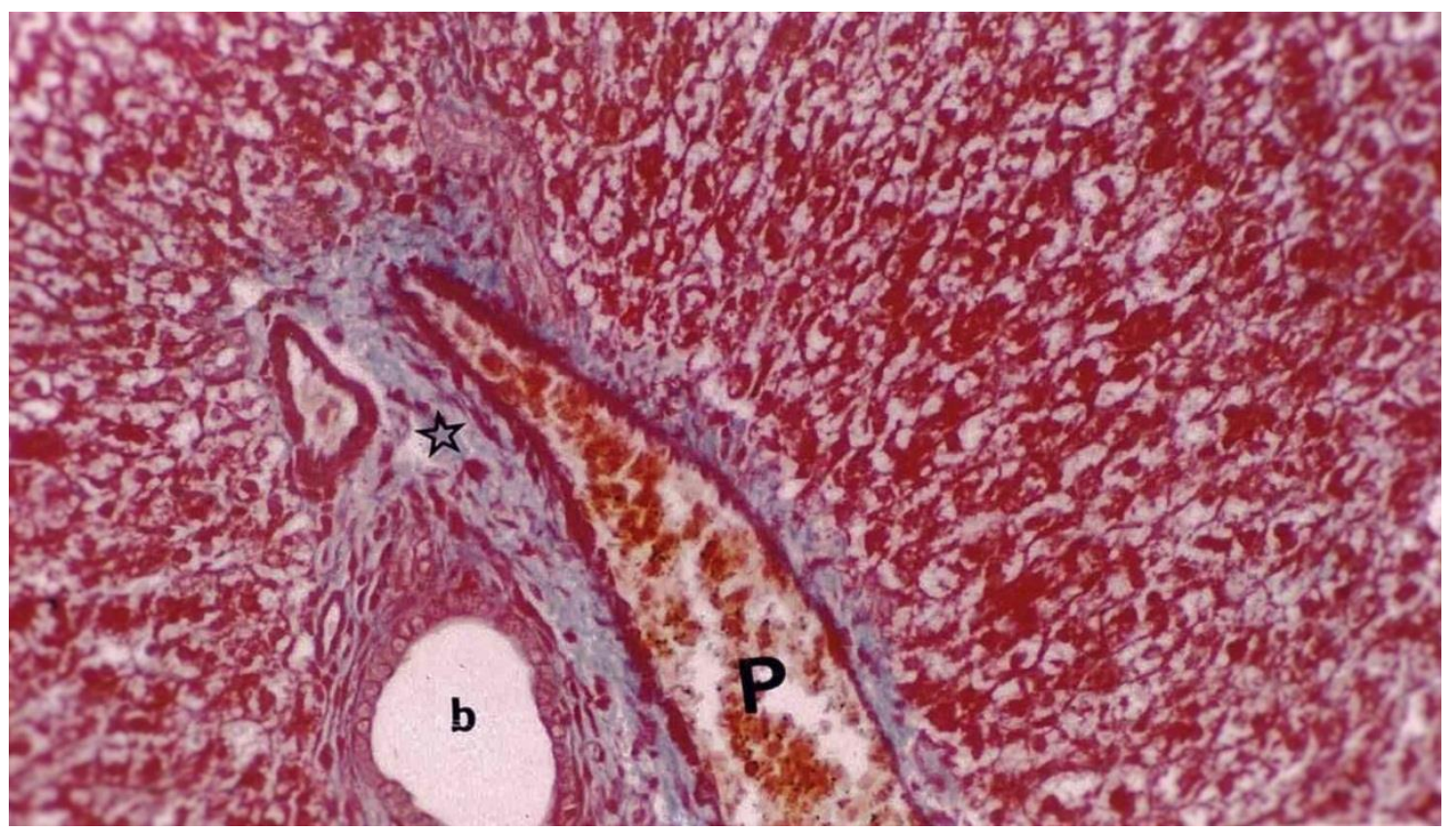

Figure (7): A photomicrograph of liver section in (DOX-treated group II) showing widespread vacuolation of the cytoplasm of the hepatocytes which being more marked peri-portally with bile duct dilatation (b) (H\&E X400) 


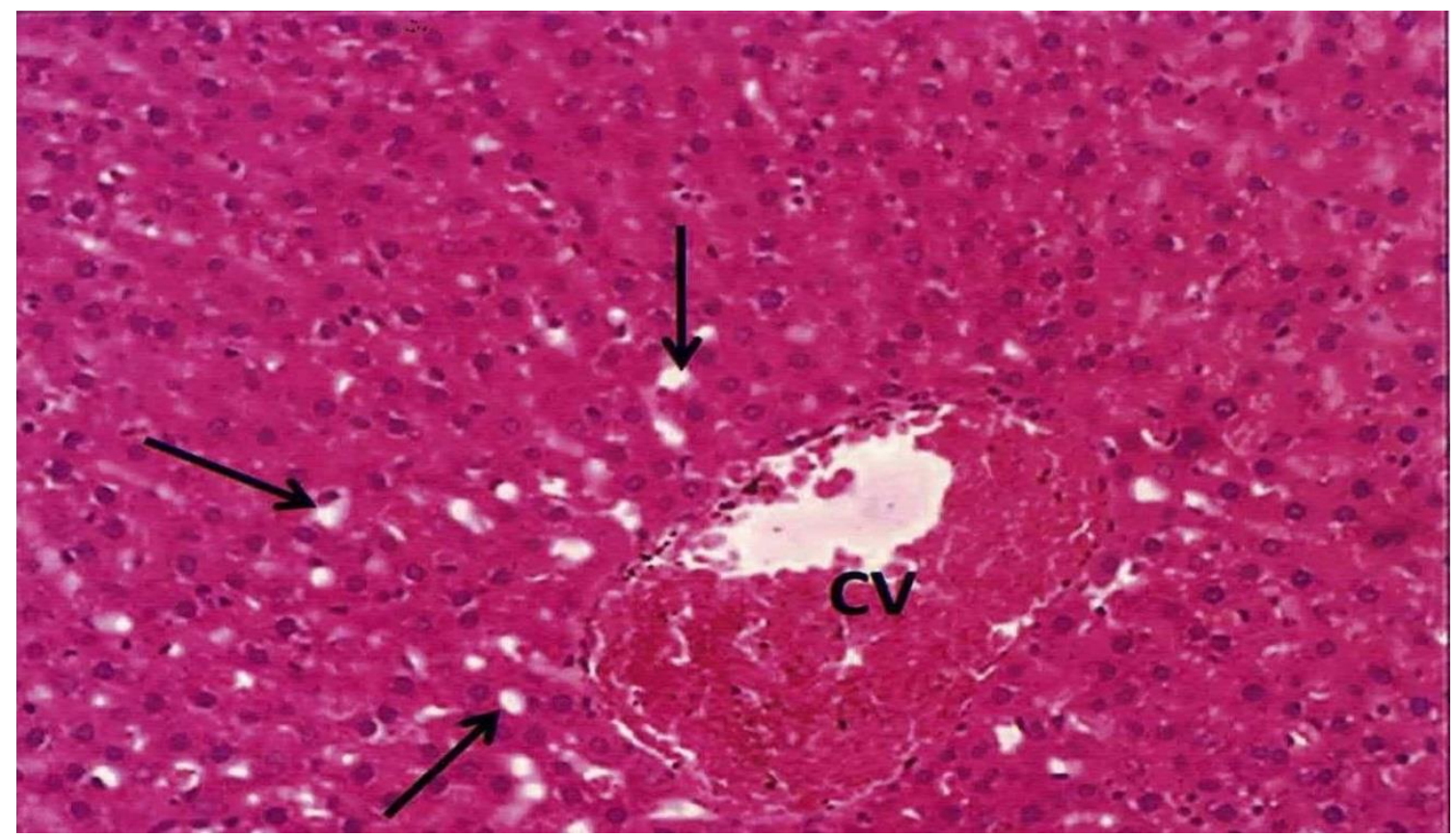

Figure (8): A photomicrograph of liver section in (DOX-treated group II) showing vacuolar degeneration (arrows) and dilated congested central vein (CV) (H\&E X200)

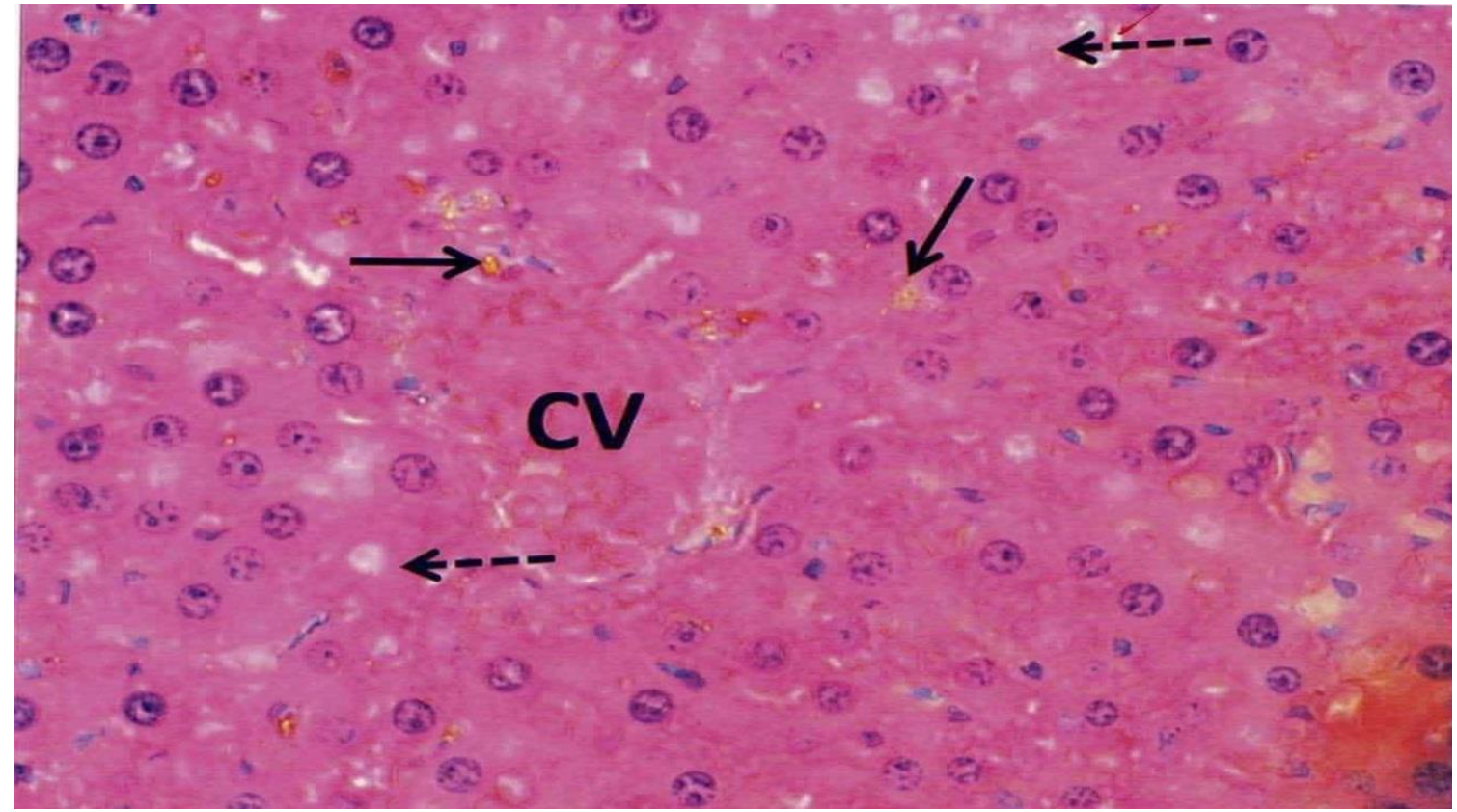

Figure (9): A photomicrograph of liver section in (DOX-treated group II) showing congested central vein (CV), loss of normal arrangement and cellular boundaries of hepatocytes, cholestasis (arrows) and areas of necrosis (dashed arrow) (H\&E X400) 


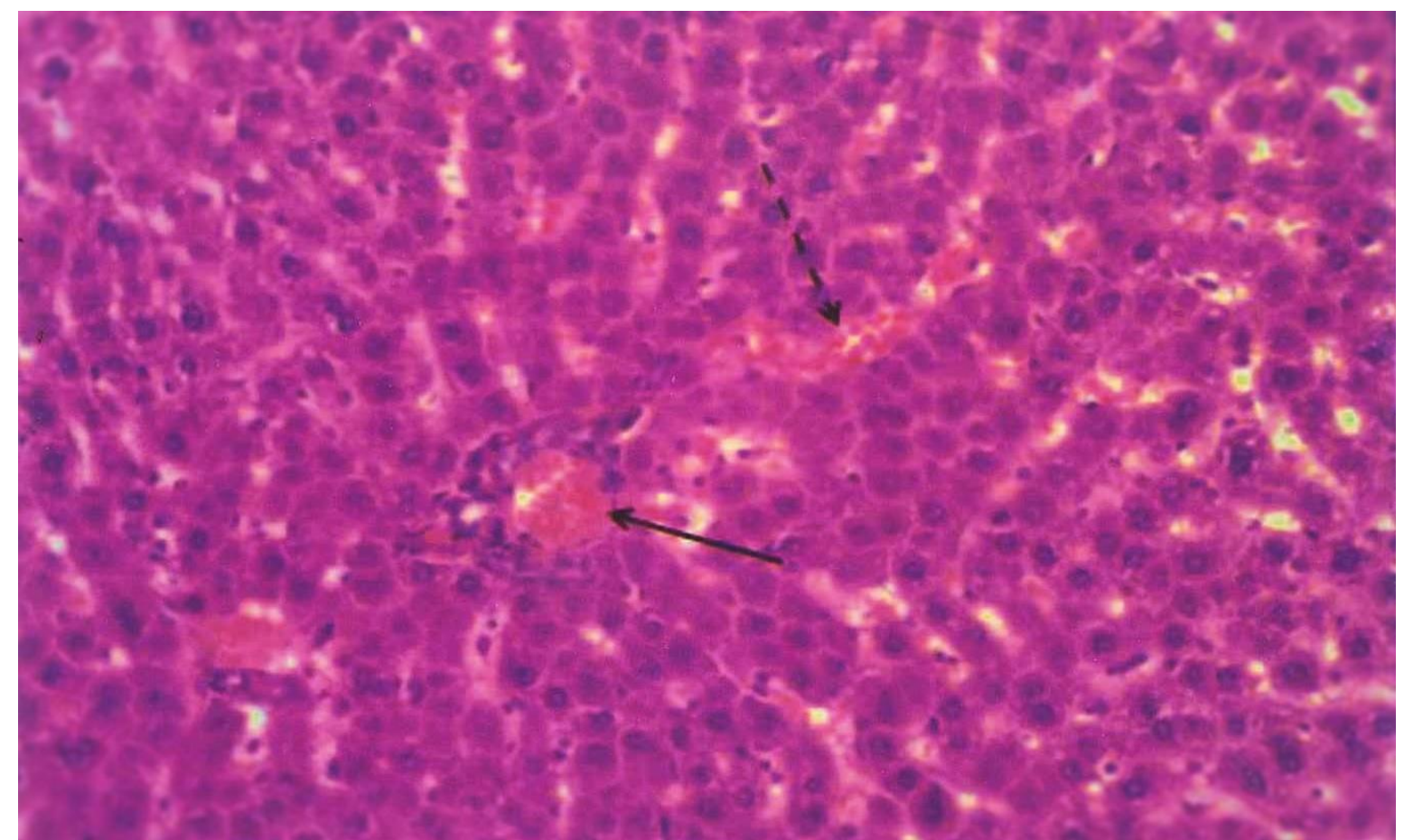

Figure (10): A photomicrograph of liver section in (DOX-treated group II) showing congested portal venule with inflammatory cell infiltration (black arrow) and dilated congested blood sinusoids

(dashed arrow) (H\&E X200)

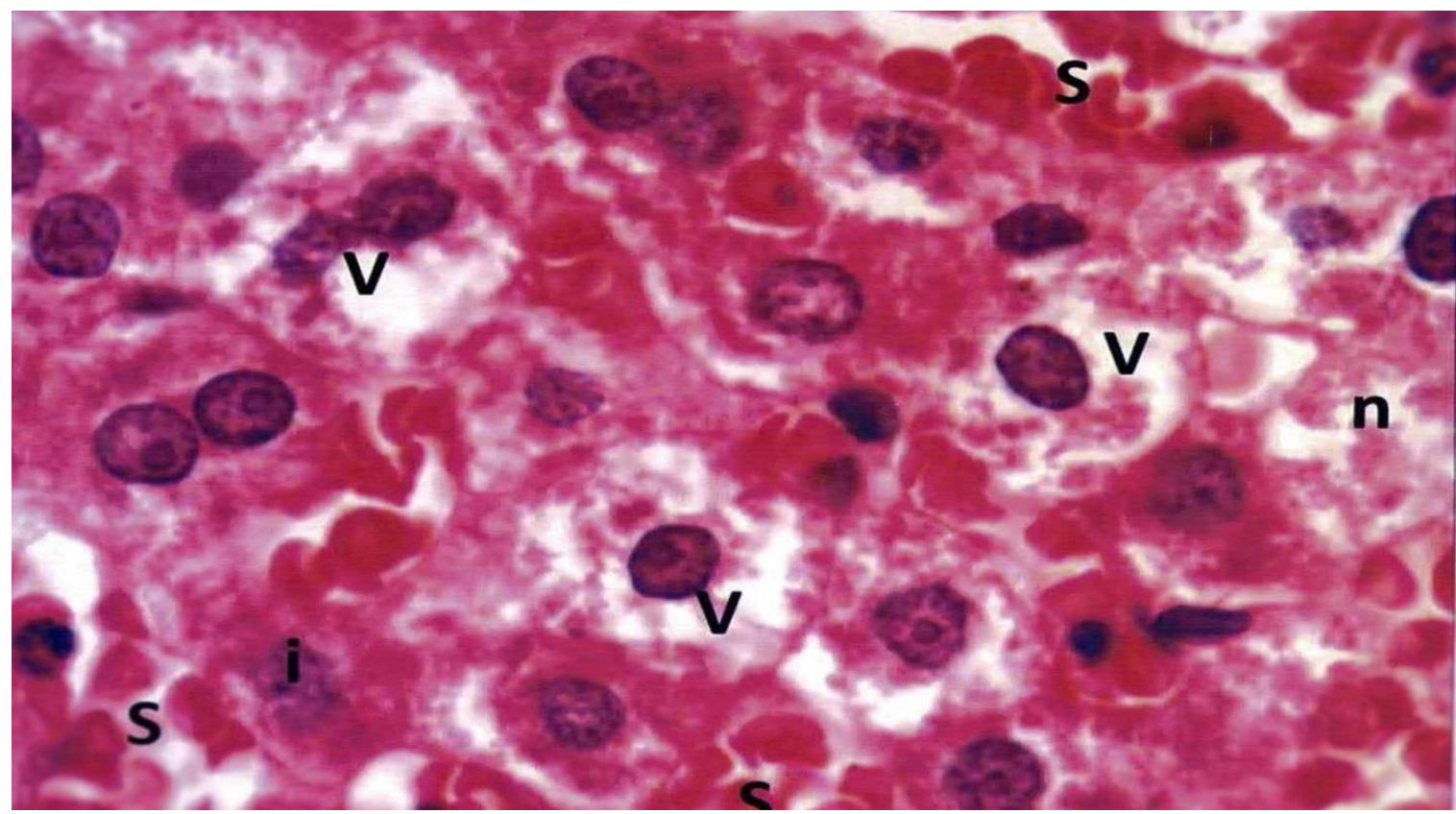

Figure (11): A photomicrograph of liver section (DOX-treated group II) showing hepatocytes with vacuolar degeneration (V), necrosis (n), karyolitic nuclei (i), separated by dilated congested blood sinusoids (S) (H\&E X 1000) 


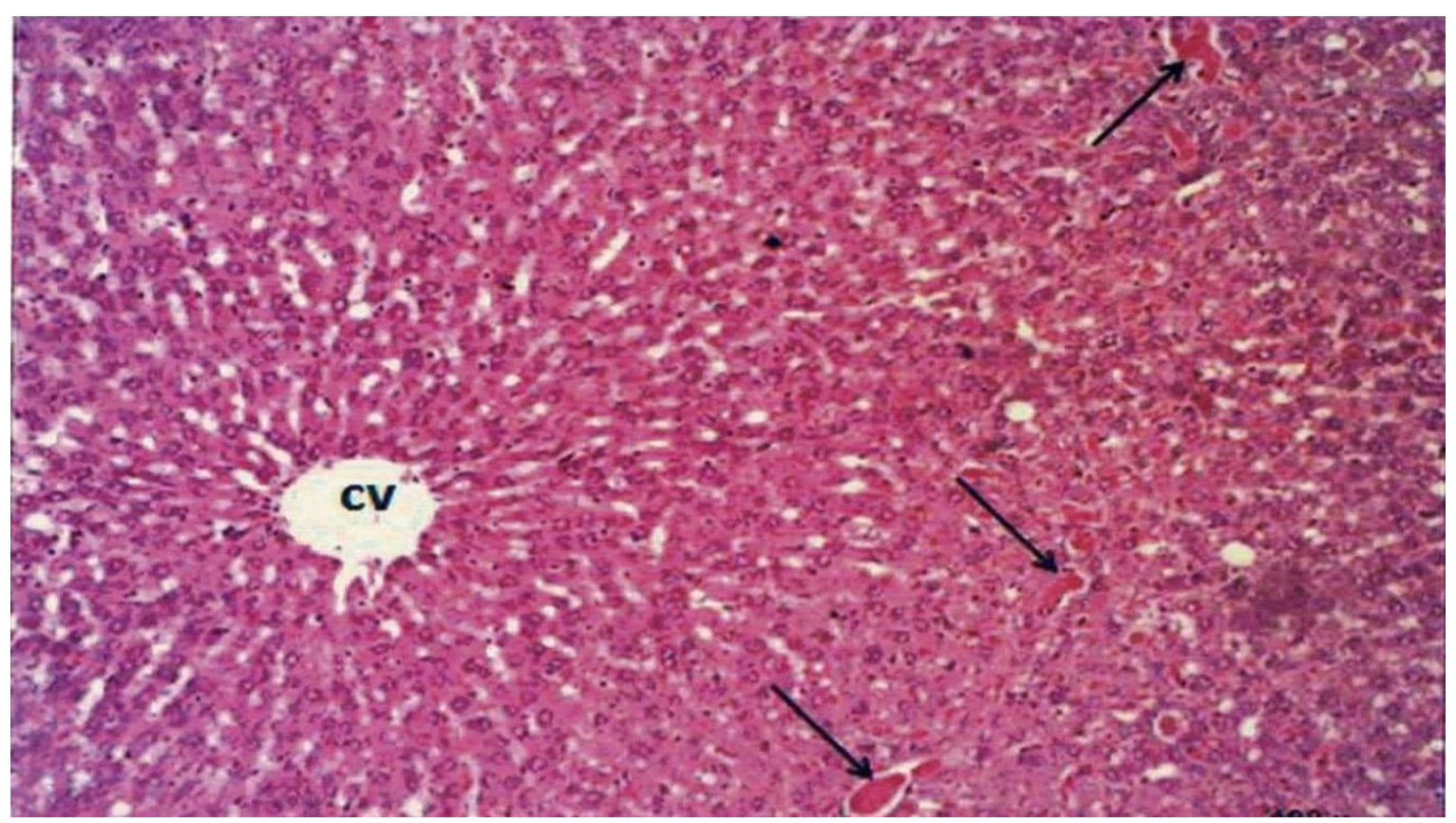

Figure (12): A photomicrograph of liver section in (DOX-treated plus QCT low dose group III) showing normal architecture of hepatic lobule and normal arrangement of hepatocytes around the central vein (CV) with dilated congested blood sinusoids (arrows) (H\&E X100)

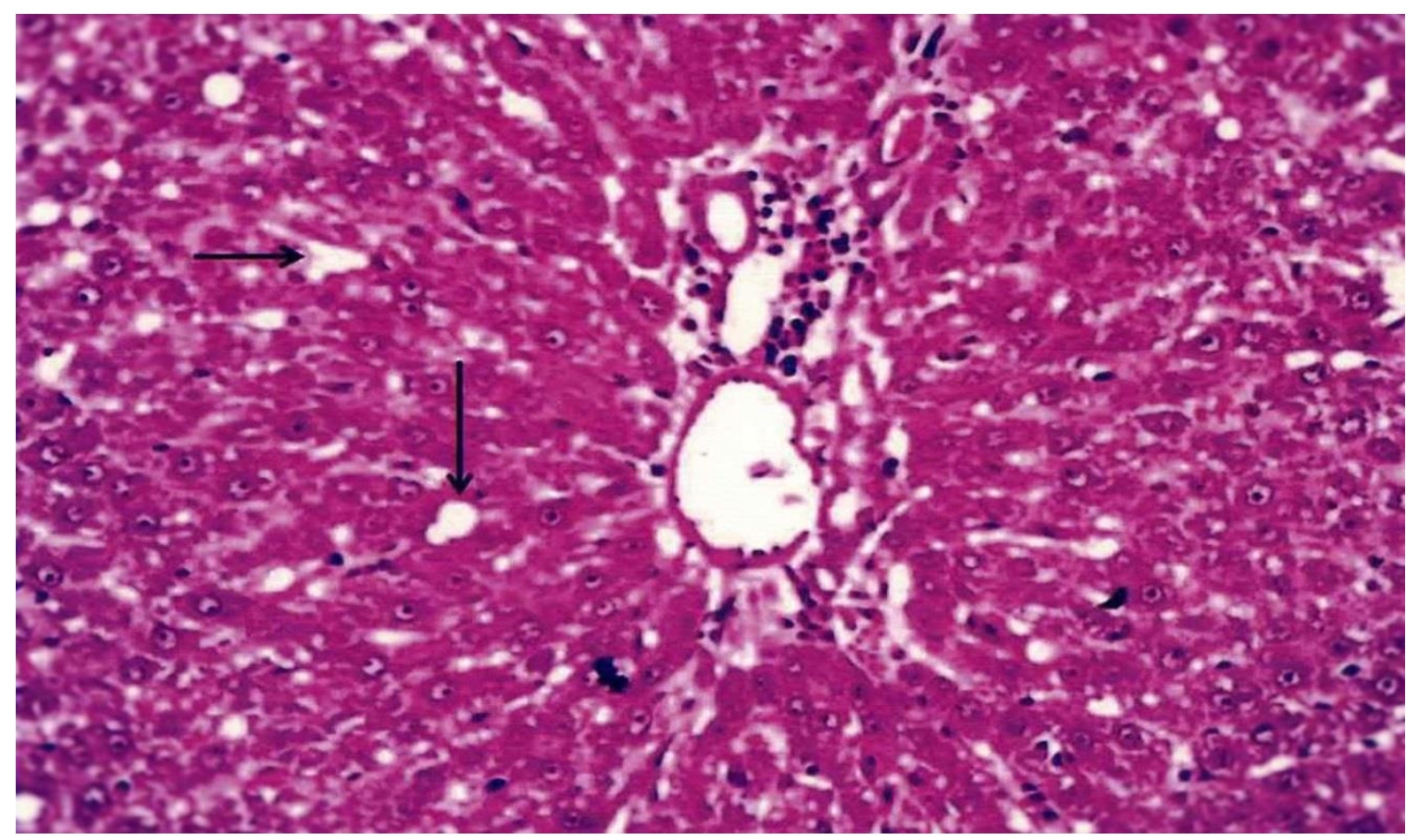

Figure (13): A photomicrograph of liver section in (DOX-treated plus QCT low dose group III) showing intact portal triad, normal sinusoids and normal arrangement of hepatic cords with few areas of vacuolar degeneration of hepatocytes in the periphery (arrows) (H\&E X200) 


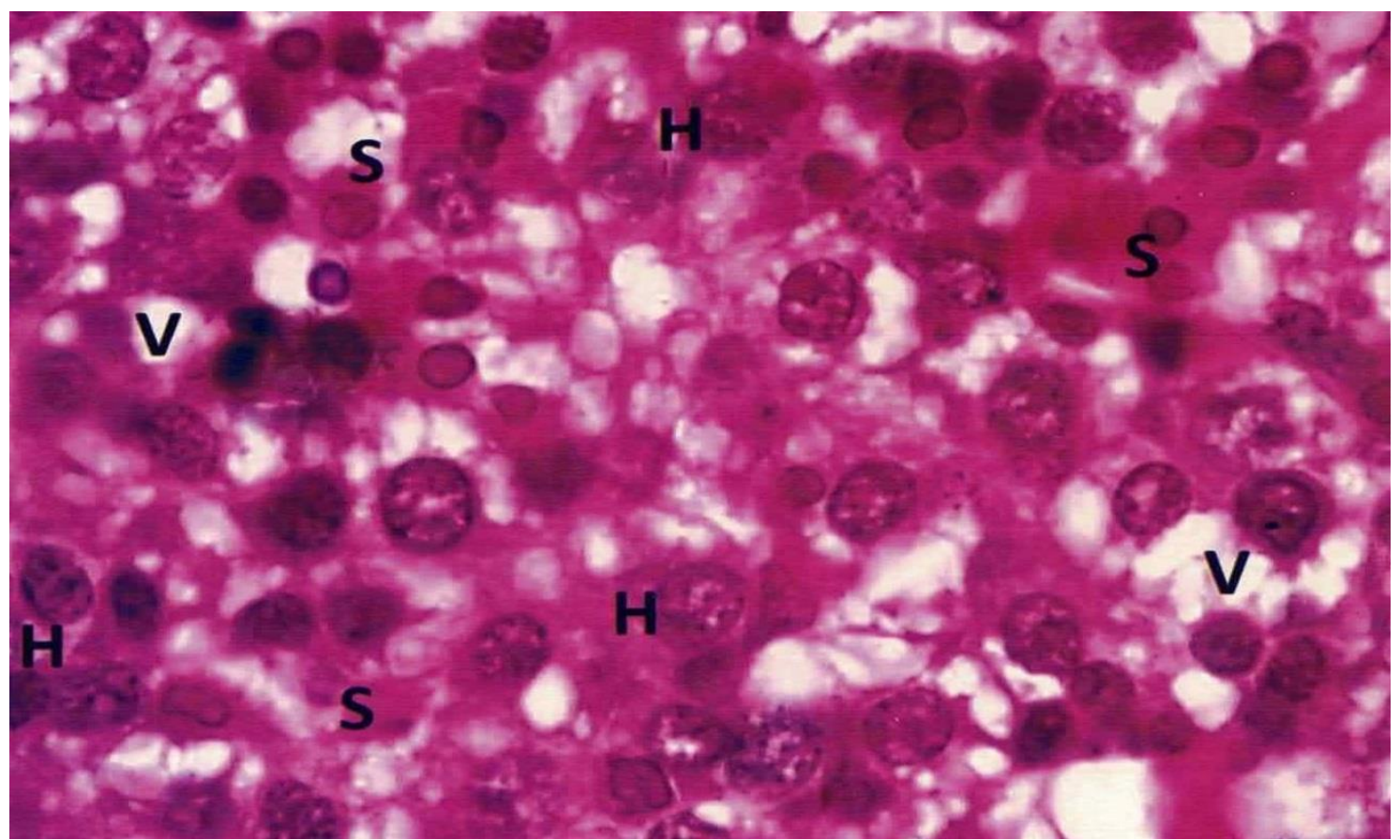

Figure (14): A photomicrograph of liver section in (DOX-treated plus QCT low dose group III) showing numerous intact hepatocytes $(\mathrm{H})$ separated by narrow sinusoids (S) filled with hematopoietic cells with few areas of vacuolar degeneration (V) (H\&E X1000)

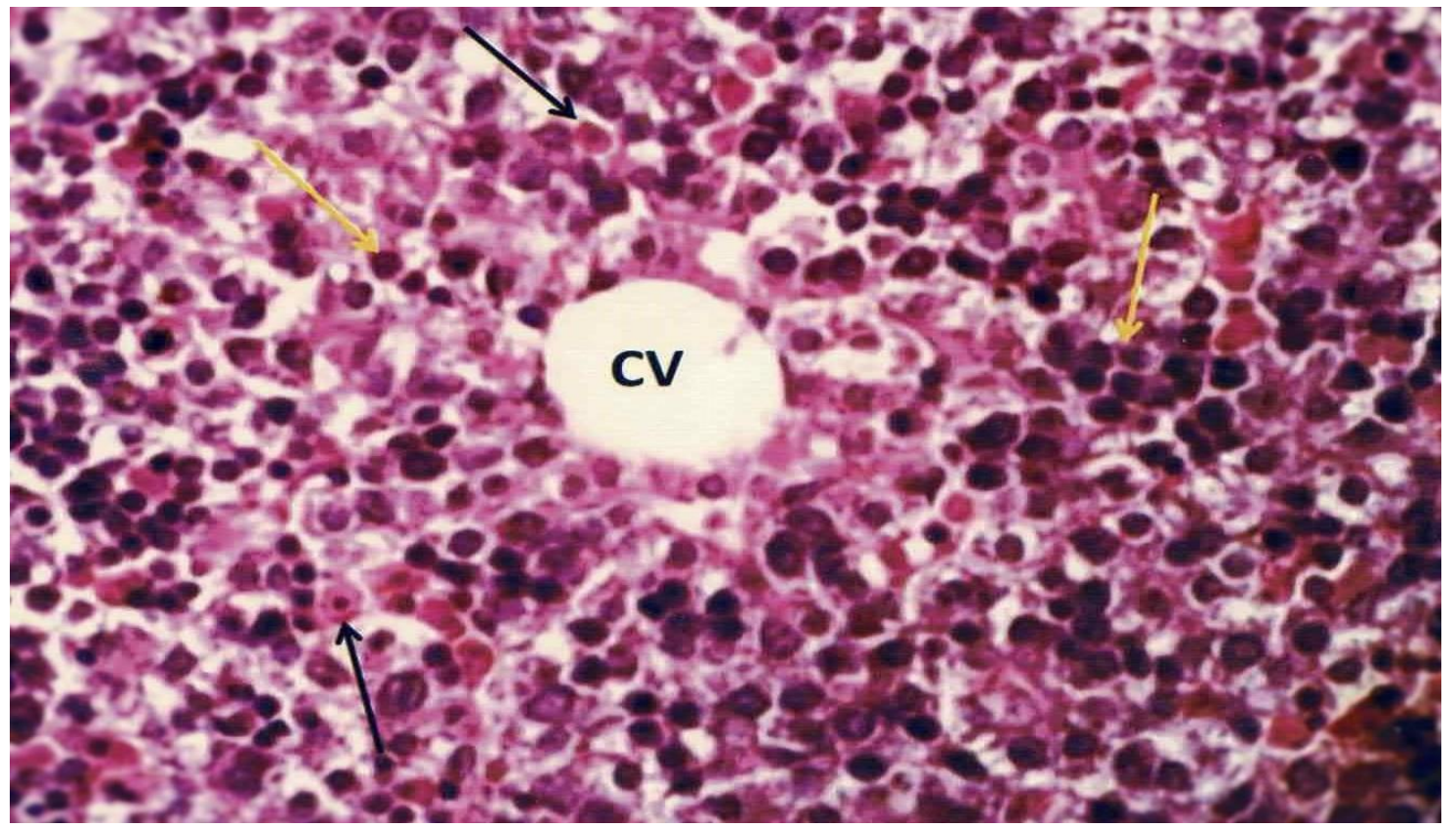

Figure (15): A photomicrograph of liver section in (DOX-treated plus QCT high dose group IV) showing polyhedral shaped hepatocytes arranged in cords around the central vein $(\mathrm{CV})$ and dispersed in the periphery of hepatic lobules. Hepatocytes are separated from each other by blood sinusoids filled with hematopiotic cells mostly lymphocytes (yellow arrows) and nucleated immature red blood cells (black arrows) (H\&E X400) 


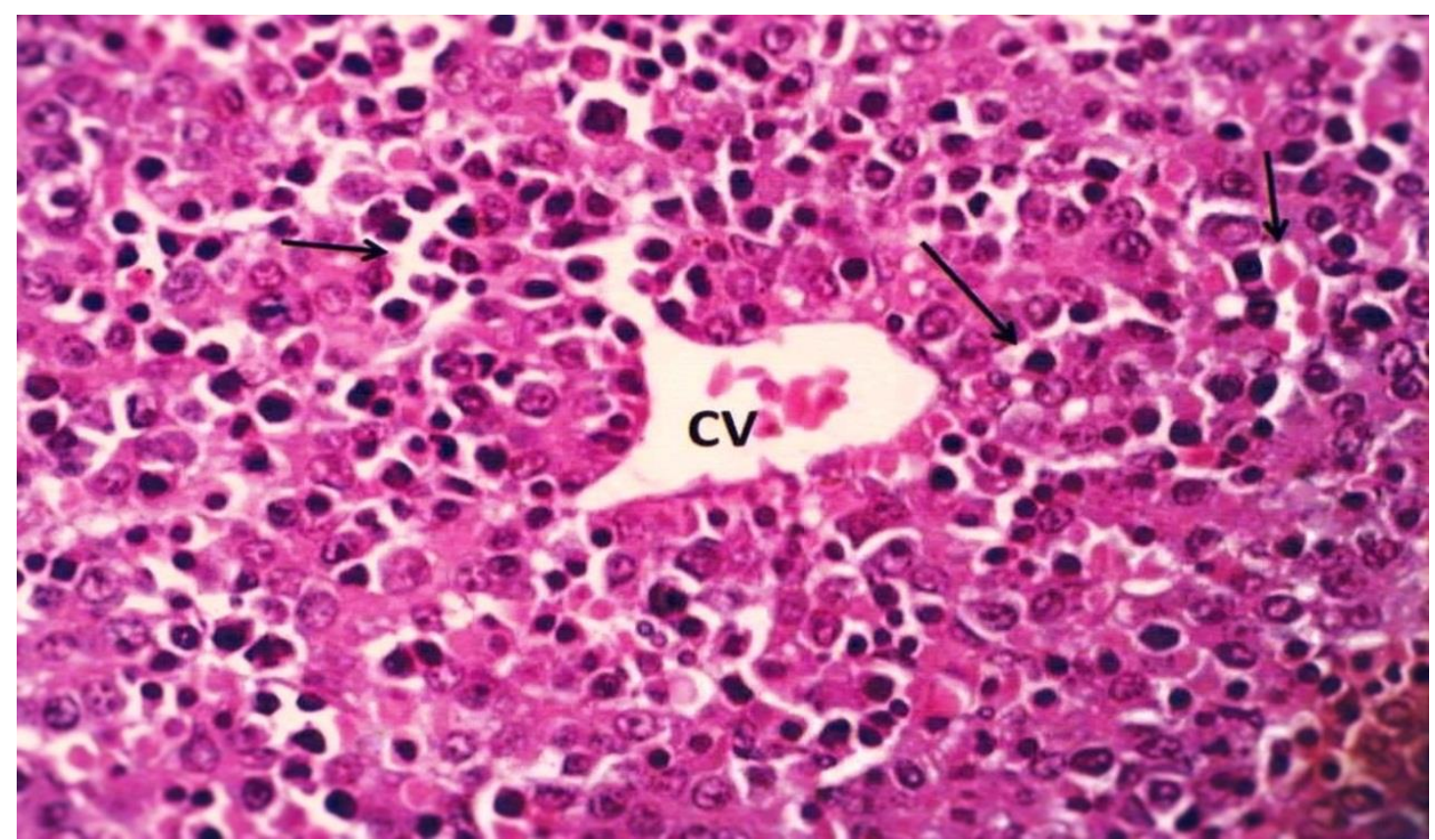

Figure (16): A photomicrograph of liver section in (DOX-treated plus QCT high dose group IV) showing central vein $(\mathrm{CV})$ surrounded by intact hepatocytes separated by sinusoids filled with hematopiotic cells (arrows) (H\&E X400)

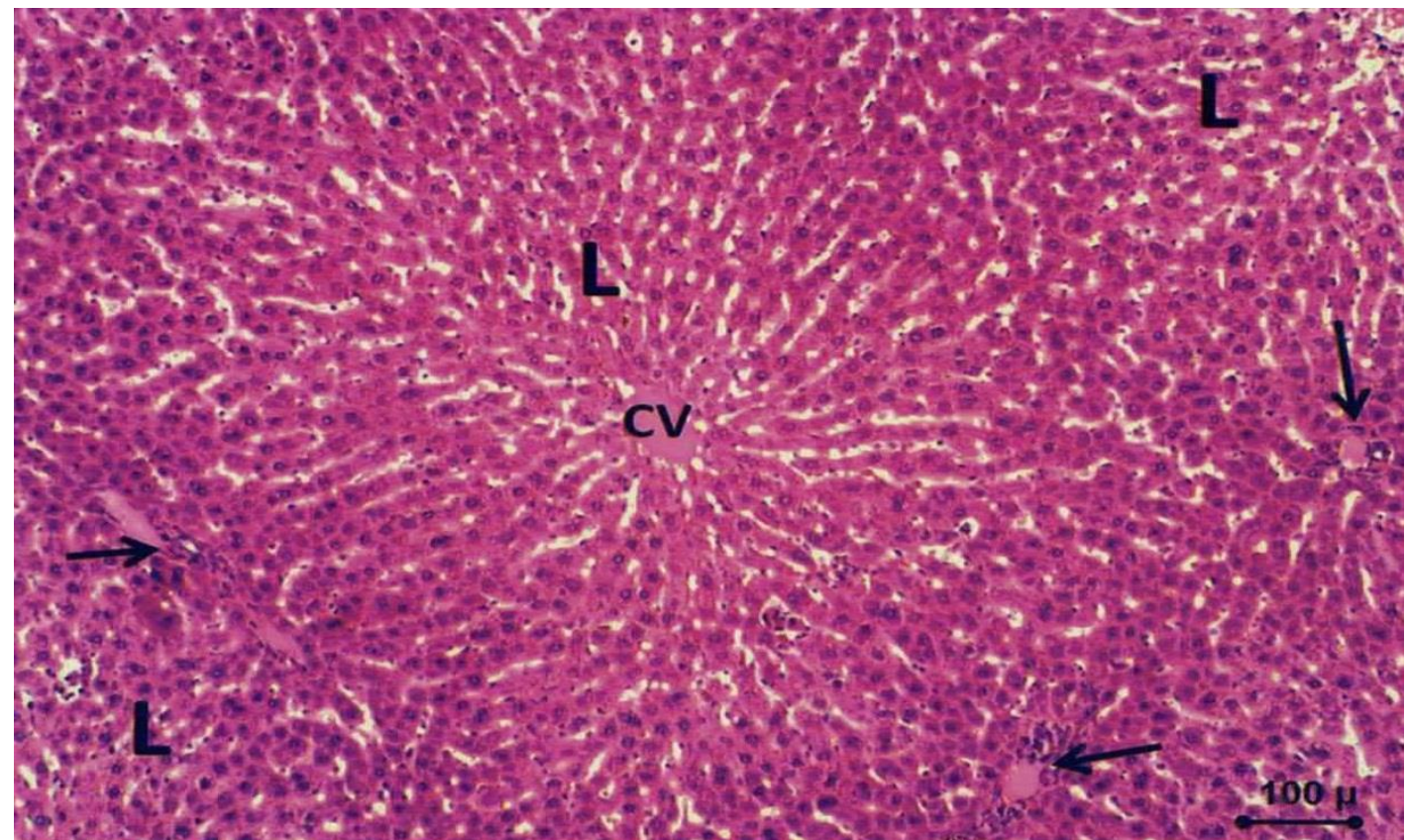

Figure (17): A photomicrograph of liver section in (DOX-treated plus QCT high dose group IV) showing hepatic lobules $(\mathrm{L})$ formed from cords of hepatocytes radiating around the central vein $(\mathrm{CV})$ and portal triads (arrows) in the angles of each lobule (H\&E X100) 


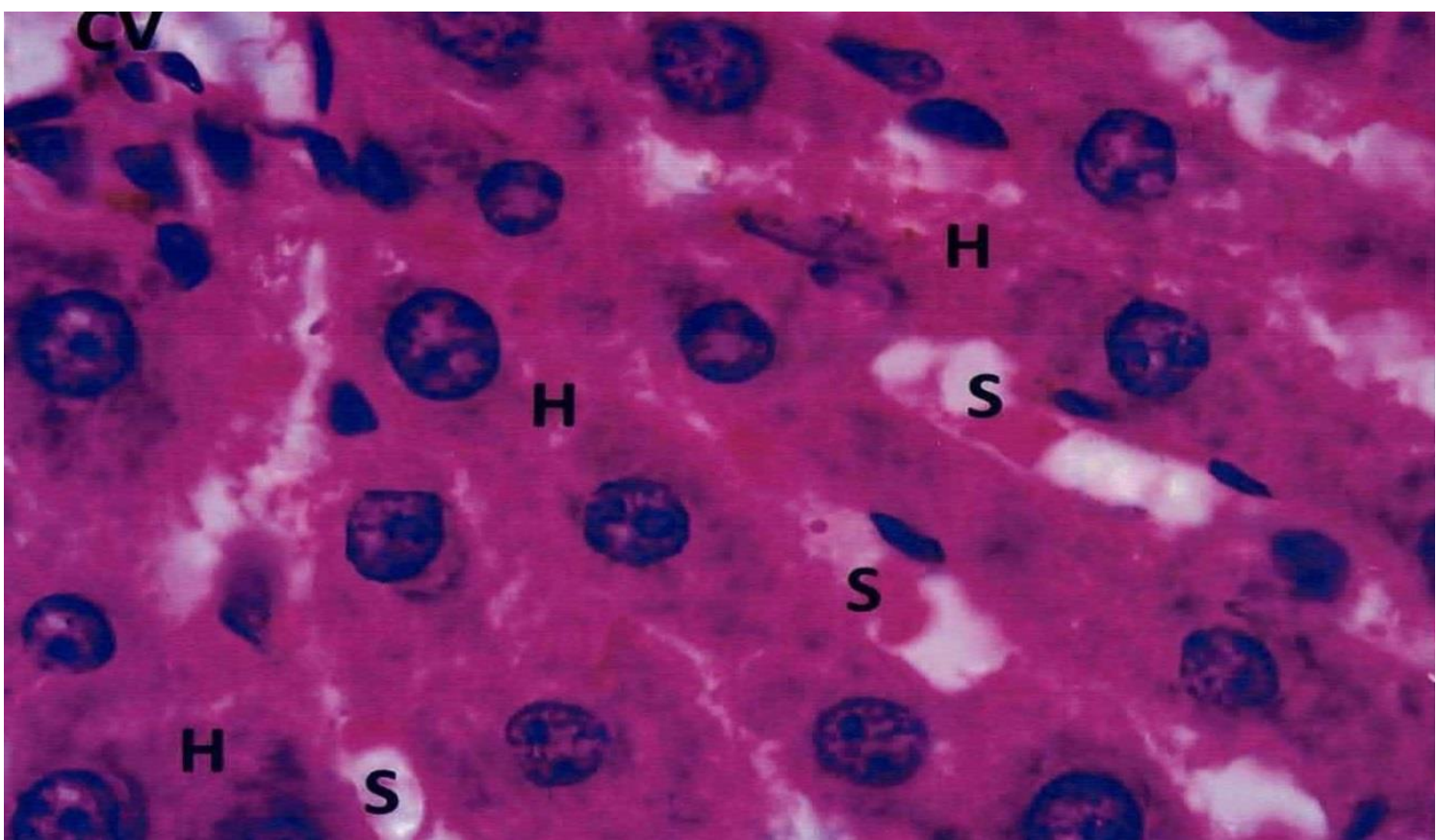

Figure (18): A photomicrograph of liver section in (DOX-treated plus QCT high dose group IV) showing arrangement of intact hepatocytes $(\mathrm{H})$ in cords radiating around the central vein $(\mathrm{CV})$ separated by blood sinusoids (S) (H\&E X1000)

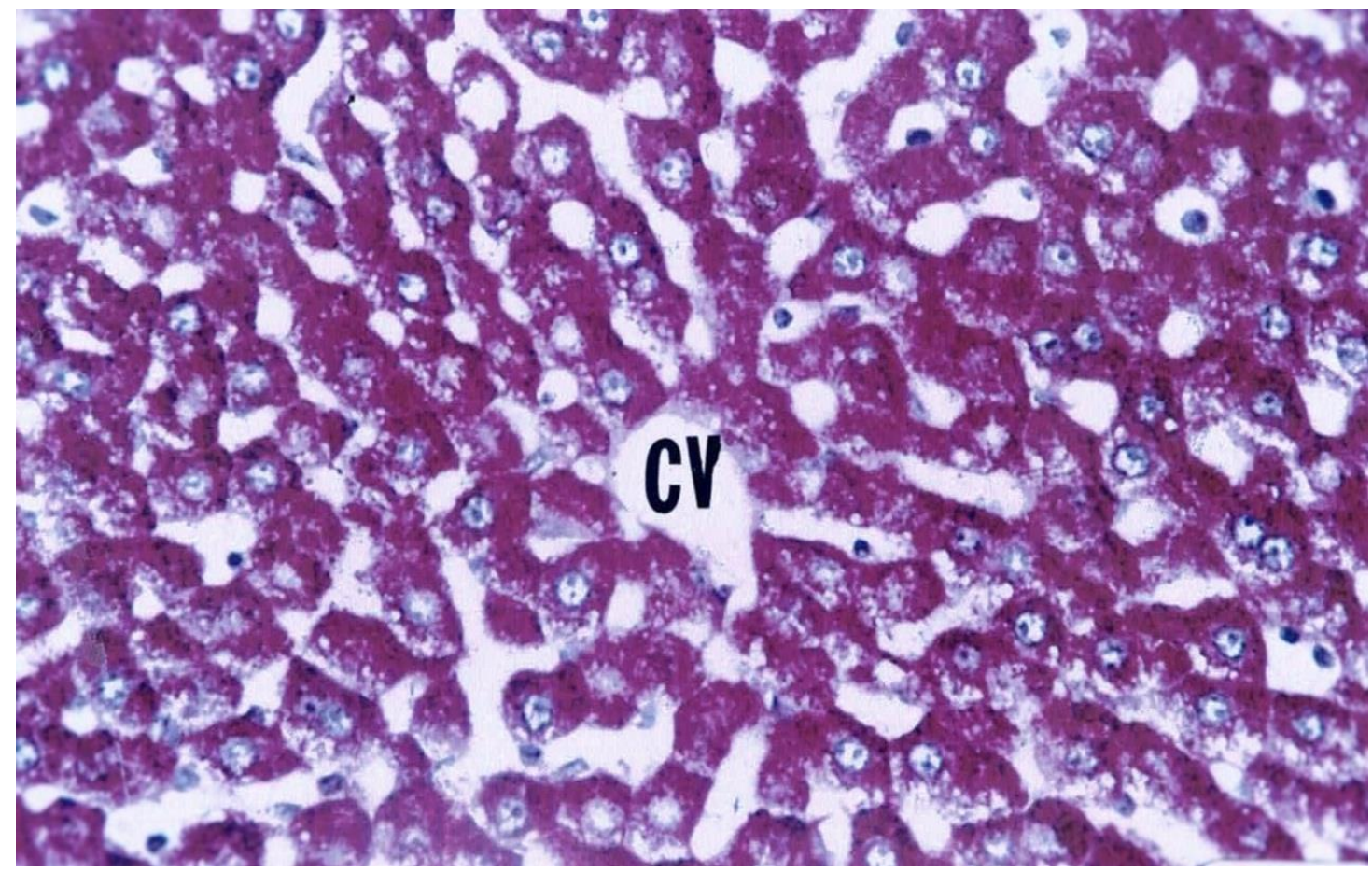

Figure (19): A photomicrograph of liver section in (control group I) showing faint positive PAS stained hepatic cells with increased glycogen deposits in the different zones of hepatic lobules especially around the central vein (CV) (PAS X 400) 


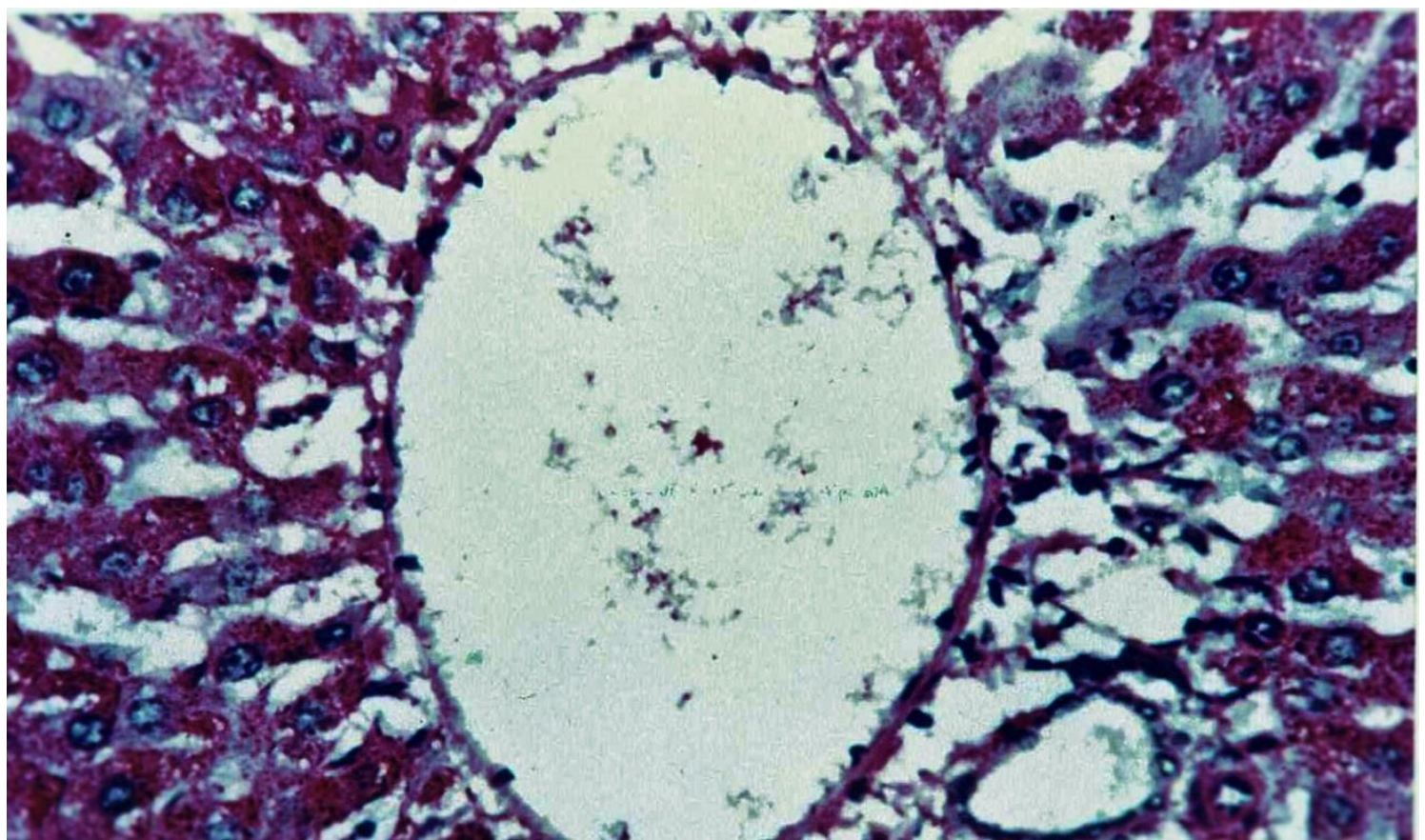

Figure (20): A photomicrograph of liver section in (DOX-treated group II) showing dense positive PAS stained hepatic cells with severe decrease of glycogen content especially around the central vein (PAS X1000)

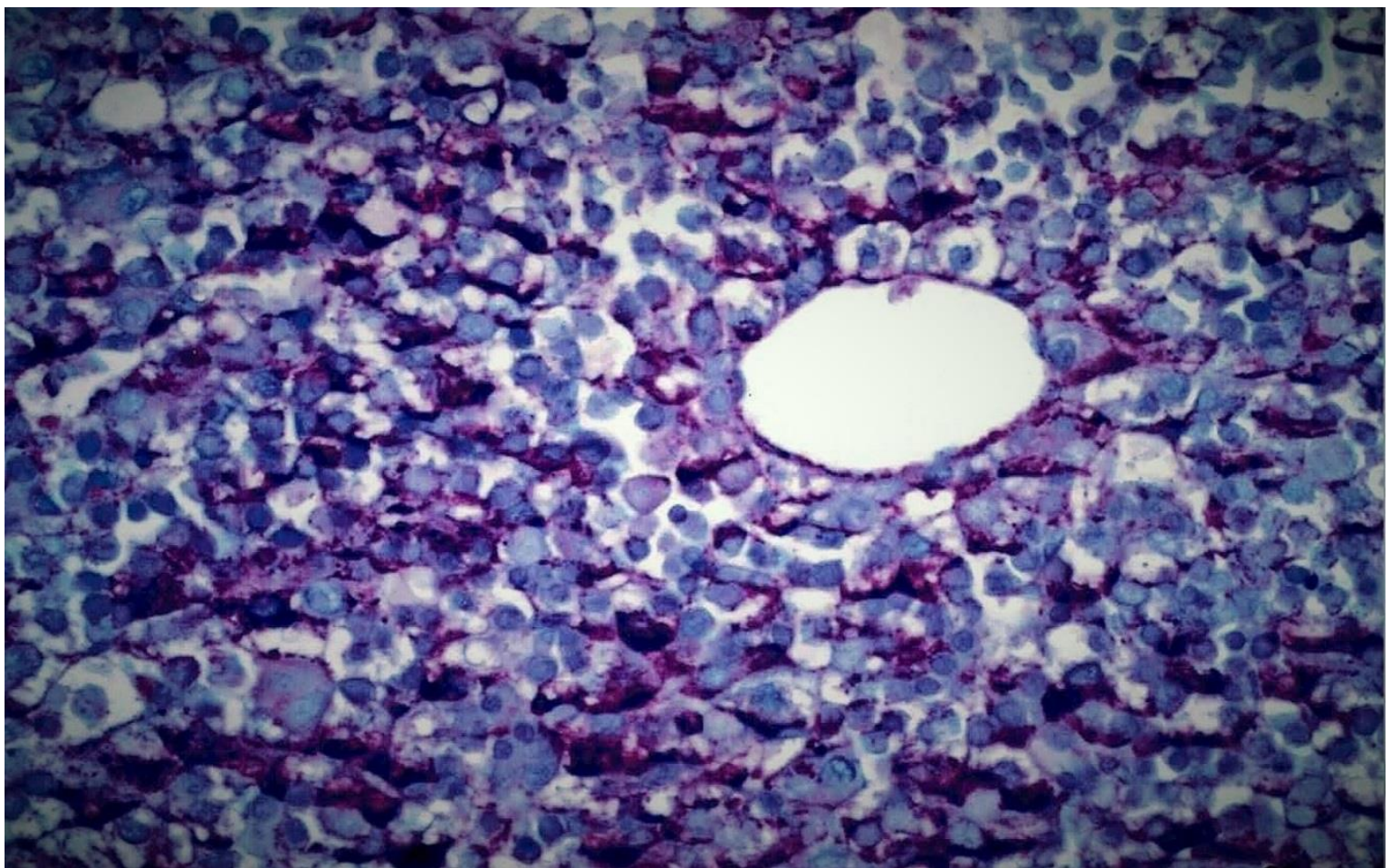

Figure (21): A photomicrograph of liver section in (DOX-treated plus QCT low dose group III) showing faint positive PAS stained hepatic cells with moderate decrease of glycogen content especially in the portal zone (PAS X400) 


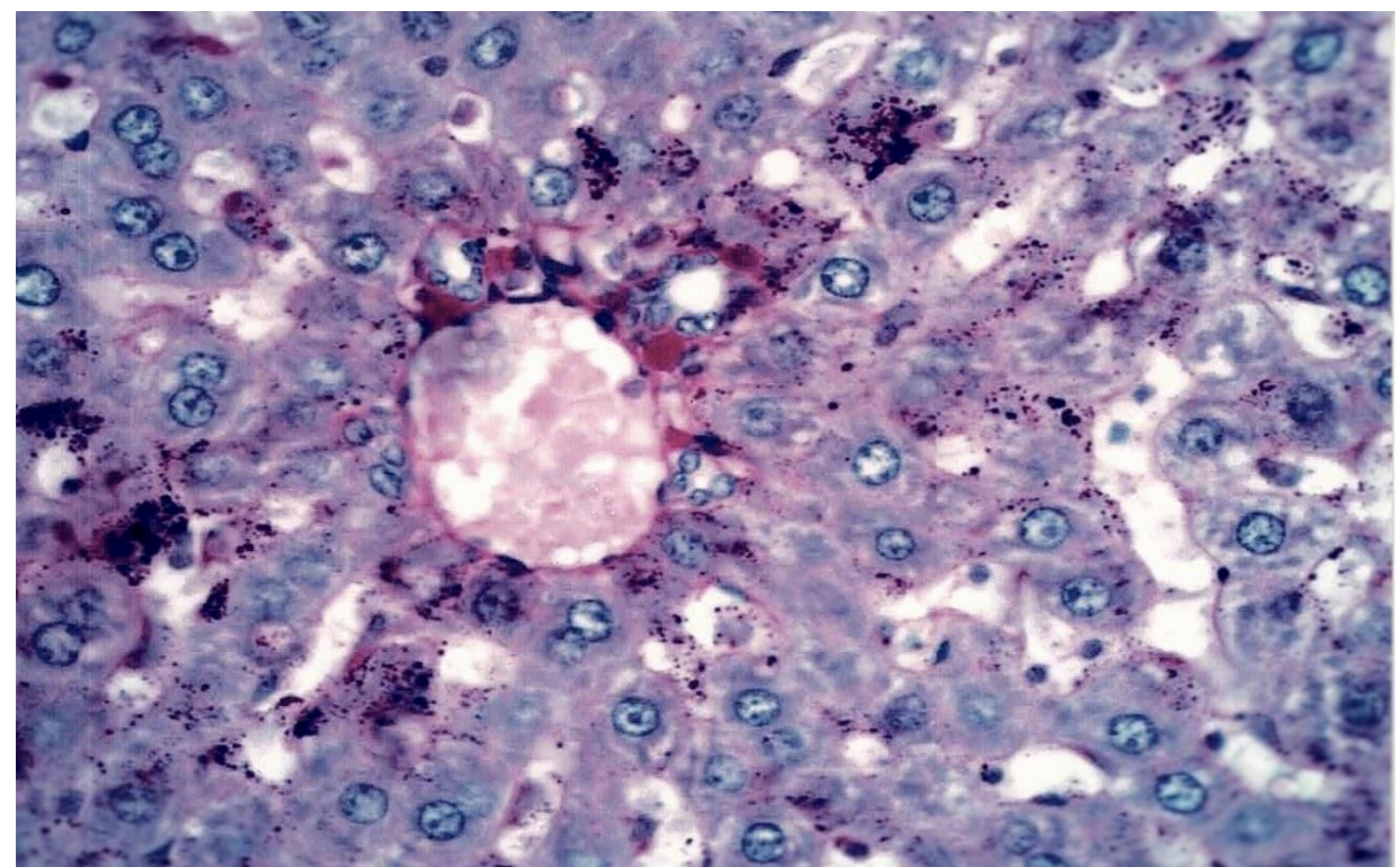

Figure (22): A photomicrograph of liver section in (DOX-treated plus QCT high dose group IV) showing faint positive PAS stained hepatic cells with mild decrease of glycogen content especially in the portal zone (PAS X400)

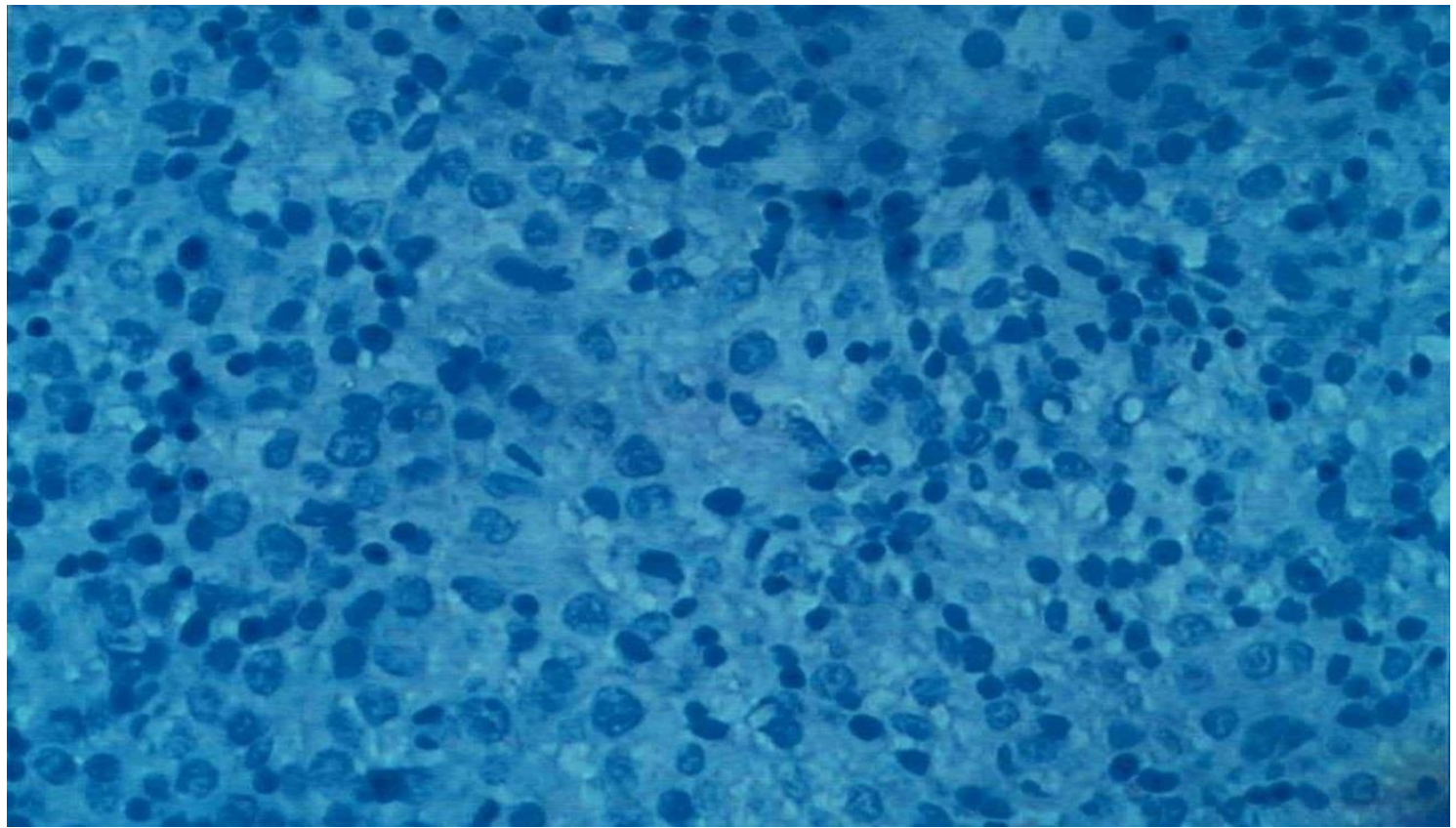

Figure (23): A photomicrograph of liver section in (control group I) showing a negative cytoplasmic Caspase-3 immuno-expression (X400) 


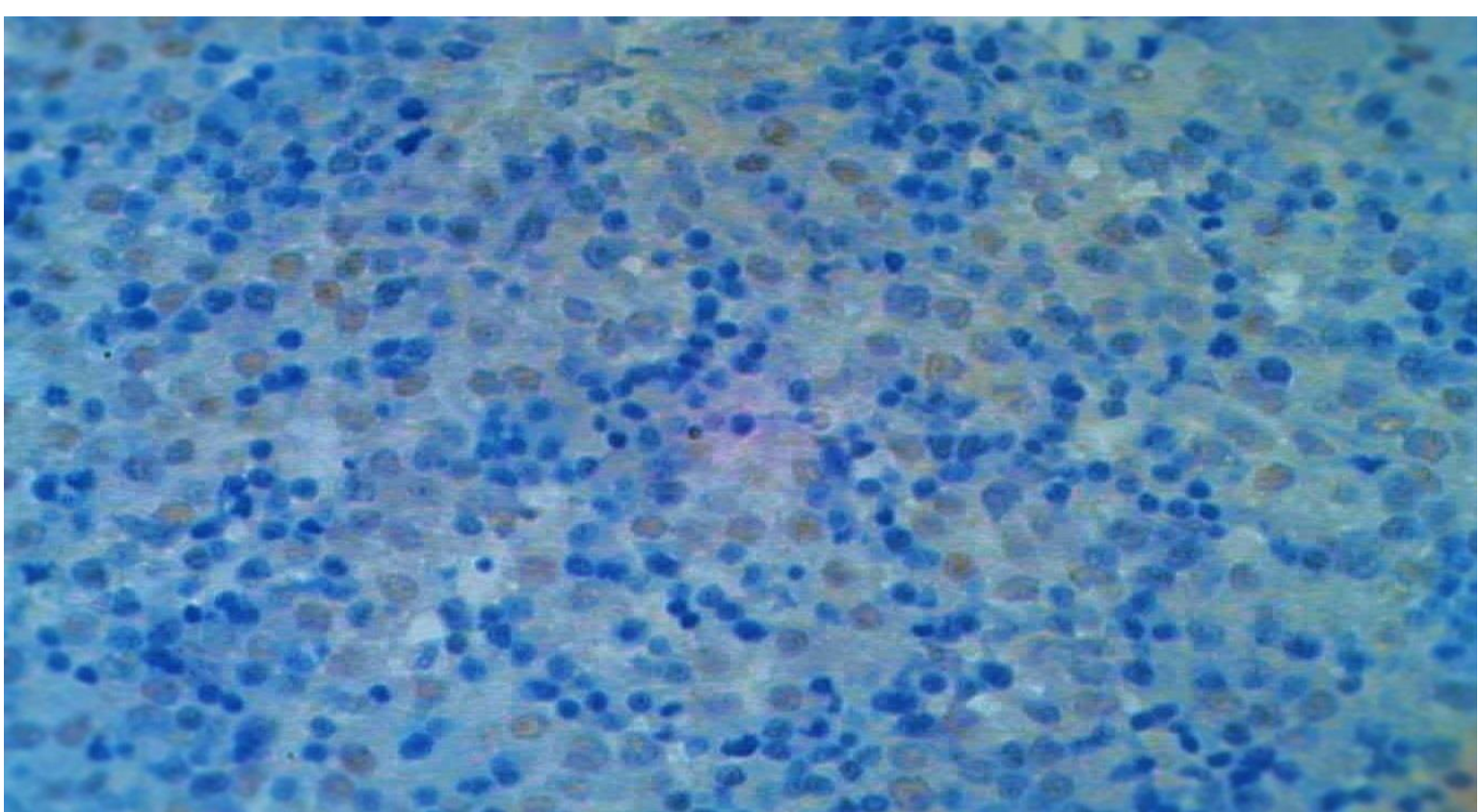

Figure (24): A photomicrograph of liver section in (DOX-treated group II) showing a dense positive cytoplasmic Caspase-3 immuno-expression (X400)

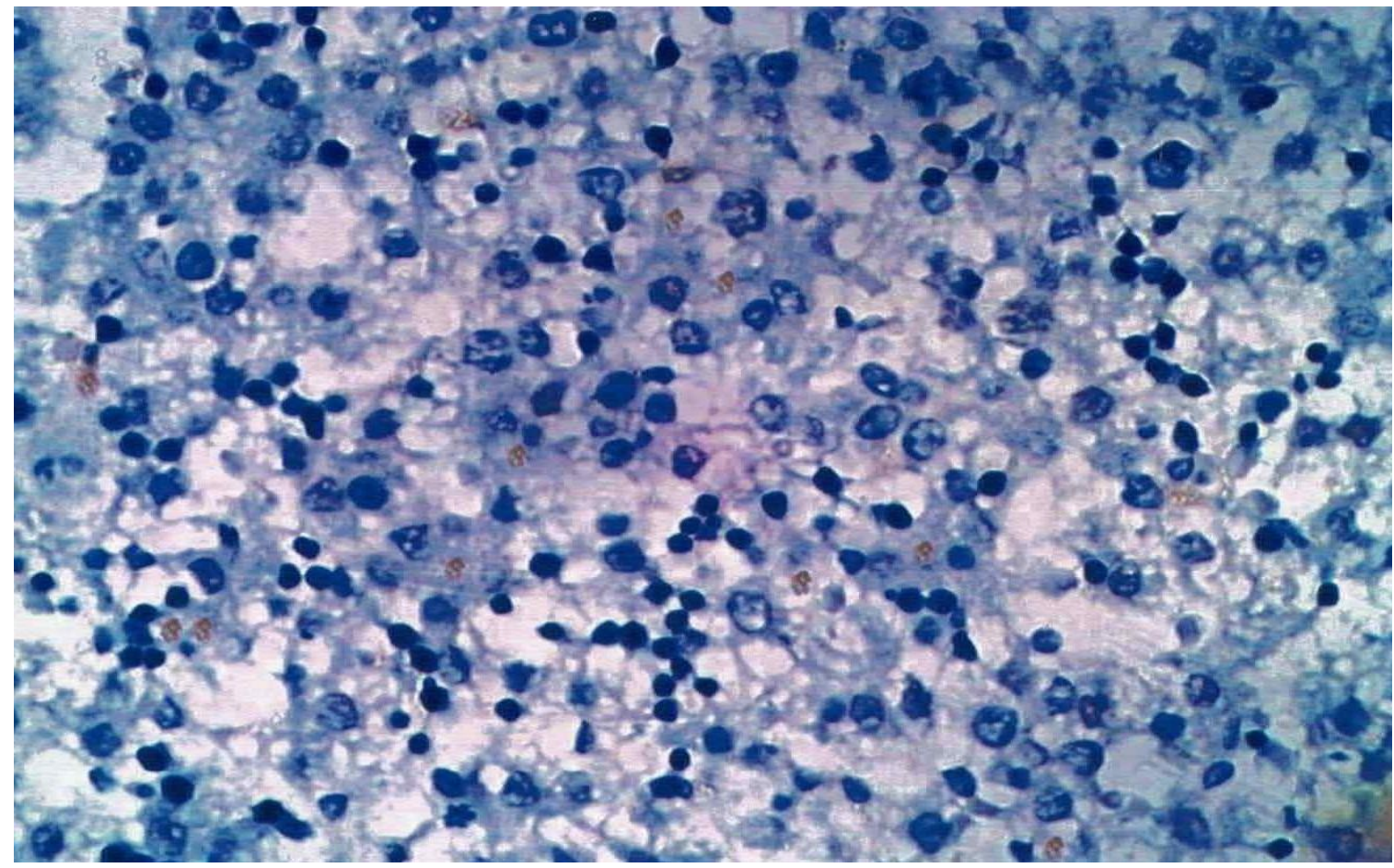

Figure (25): A photomicrograph of liver section in (DOX-treated plus QCT low dose group III) showing few traces of positive cytoplasmic Caspase-3 immuno-expression (X400) 


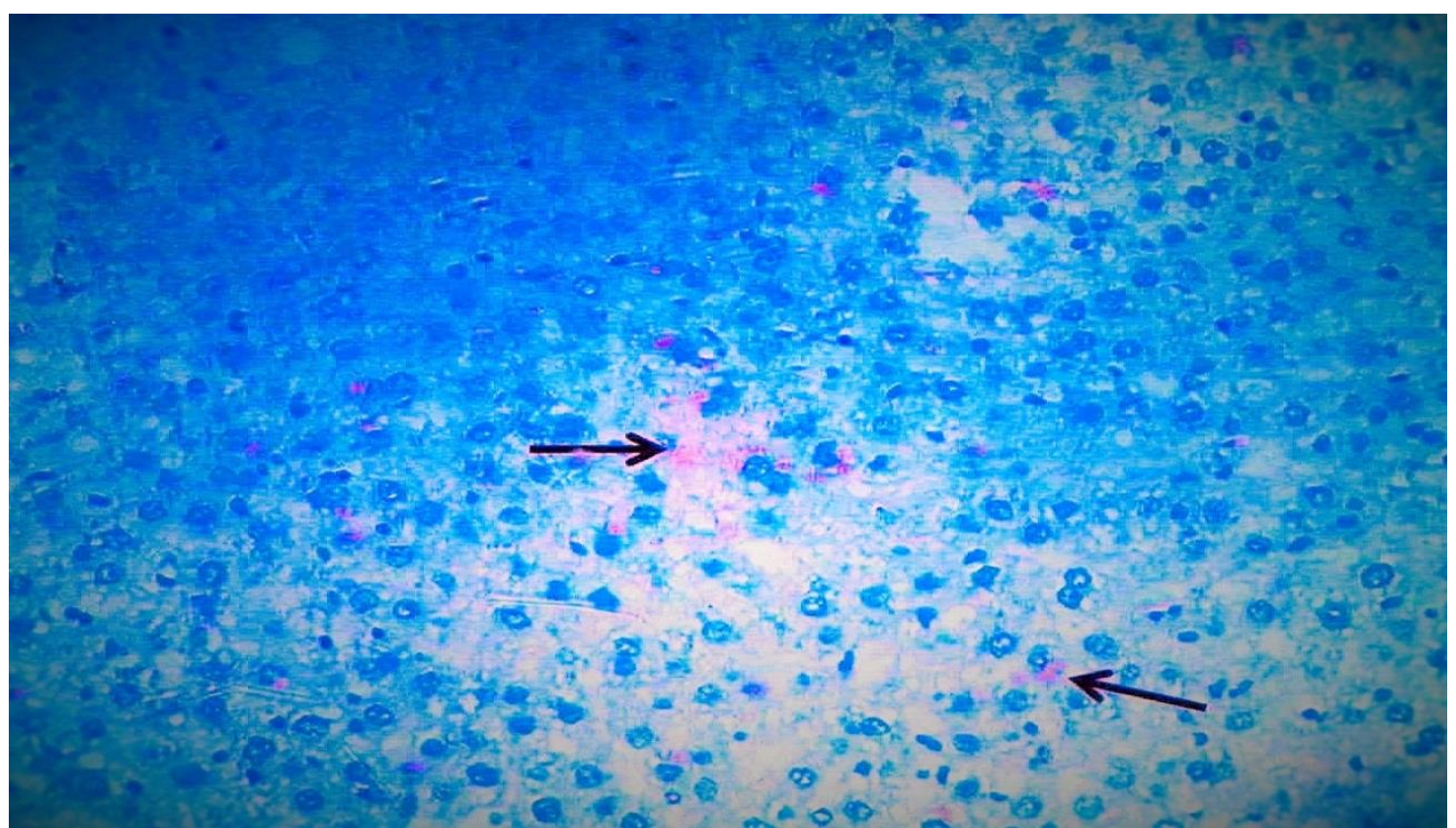

Figure (26): A photomicrograph of liver section in (DOX-treated plus QCT high dose group IV) showing very few traces of positive cytoplasmic Caspase-3 immuno-expression (arrows) (X400)

\section{Discussion}

Liver maintains the body's internal environment as it controls the metabolism of carbohydrate, protein and fats and it has a role in both metabolism and detoxification of toxicants, which may result in liver injury. Liver injury is attributed to oxidative stress, which can result in liver diseases that range from transient elevation of liver enzymes to fibrosis and cirrhosis (Pandit et al., 2012). The current study stated that, the liver weight increase in the DOX-treated rats which may be attributed to the oxidative stress while the body weight decrease may be due to decreased food intake. Those results are in accordance with Beshay et al, (2011) study results which stated that DOX-treated rats lose about $5 \%$ of body weight when compared with control. Serum ALT and AST are markers for detection of hepatotoxicity so, serum enzyme levels is used to assess liver damage as membrane necrosis lead to diffusion of the intracellular enzymes to the serum and elevation of their levels which indicate liver membranes integrity loss (Etim et al., 2006). ALP and total bilirubin high levels were also associated with hepatic cell dysfunction (Shehab et al., 2015). The current study stated that DOX administration led to significant increase in ALT, AST, ALP, total bilirubin serum level and MDA in comparison to control. That results denote a hepatocellular damage and hepatic dysfunction as stated by Alshabanah et al, (2010) results as liver damage may induced by the free radicals and their oxidative stress. DOX tend to generate superoxide anions and peroxynitrite radicals in drug metabolism in liver which initiate Reactive Oxygen Radicals (ROS)-lipid peroxidation and lead to damage of hepatocytes and elicit ALT and AST to serum (Barakat et al., 2018). Significant improvement in liver enzymes and GSH level were observed in QCT treated groups in comparison to control and DOXtreated groups. Those results are in accordance with
Jambhulkar et al, (2014) results which stated that the altered biochemical parameters were appeared near their normal ranges on QCT administration with DOX group. The mechanism may be attributed to that QCT has the ability to increase the mRNA expression of liver enzymes which involved in drug metabolism in an isoenzyme-specific manner (Odbayar et al., 2009). QCT have been reported to interact with membrane lipid components, with a resultant protection of the membranes against oxidative damage (Verstraeten et al., 2015). A recent study stated that DOX-treated group can increase both ALT and AST enzymes activity because of the liver damage and it is confirmed by the histological results (Barakat et al., 2018). The present results showed that DOX-treated group sections which stained with H\&E showed focal hepatocyte necrosis and the hepatotoxicity that resulted are in accordance with Jambhulkar et al, (2014) and Mete et al, (2016) results which stated a parenchymal necrosis and proliferation of biliary ducts in DOXtreated group. Vacuolation of hepatocytes was reported as one of cellular defensive mechanism as they can collect the harmful elements and prevent their interfering with the biological functions of these cells and Pyknosis and karyolysis of the nuclei may be attributed to the loss of functional efficiency (ALMosaibih, 2013). The present results showed that DOX-treated sections appeared with high positive PAS stained hepatocytes which illustrated increase of glycogen contents and that results are in accordance with results of Ahmed et al (2020) study. QCT treated sections which stained by H\&E, illustrated its protective effect as the normal architecture was observed and the histo-pathological changes which found in the DOX-treated group were decreased in the DOX plus QCT treated groups. The present results are in accordance with Jambhulkar et al, (2014) results 
which stated that administration of QCT with 100 $\mathrm{mg} / \mathrm{kg}$ protected hepatic tissues from DOX toxicity. The protective effect of QCT against hepatotoxicity in the current study is agree with a recent study which stated that QCT limit the methotrexate induced hepatotoxicity in rats as it is considered as a potent antioxidant (El-Bana and Kamal 2019). Studies documented that acute DOX toxicity alters cytochrome P450 expression in mice liver while QCT can increase the P-450 reeducates activity in human liver, and suppresses the expression of the pro-apoptotic Bax gene and increases the anti-apoptotic Bcl-2 gene in cells under the oxidative stress (Zordaky et al., 2011 and Suematsu et al., 2011). The QCT treated sections which stained with PAS showed faint staining which indicated low glycogen contents in hepatocytes. It indicated that QCT protecting the liver cells as it may has a benefit in DOX treatment as it can increase its therapeutic efficacy against hepatic cancer. The results are in accordance with Wang et al, (2012) results which documented that QCT can reverse hepatic damage which resulted from DOX administration in mice. The present results documented that DOX treated animals' sections revealed increased apoptosis which attributed to the oxidative stress and increased cytoplasmic Caspase-3 immune-expression activation (El-Sayyad et al, 2014). DOX prompted hepatotoxicity, may be due to hepatocytes' apoptosis that is associated with a significant DNA degradation along with increased Caspase-3 protein expression (Barakat et al., 2018). QCT administration led to improvement of the Caspase-3 immuno-expression activation as it aids in preventing apoptosis which induced by lipid peroxidation as it decreases the hepatic lipid peroxides because it is considered as a potent anti-oxidant (Arzu e al, 2004). ROS and oxidative stress are considered as apoptosis triggers and modulators. ROS-induced apoptosis requires other cell death signaling pathways as c-Jun N-terminal Kinase (JNK) to regulate the expression of various apoptosis proteins engaged in hepatotoxicity (Chao et al., 2009). The mechanism of JNK-dependent apoptosis has been suggested to involve activation of Caspase-3 via phosphorylation of Bcl-2 family proteins. Studies stated that QCT is able to attenuate the toxicant-induced apoptosis by the inhibition of JNK activation and can prevent apoptosis by altering the expression of both $\mathrm{Bax}, \mathrm{Bcl}-2$ and Caspase 3 (Shi et al., 2009 and Kim et al., 2009).

\section{Conclusion}

This study concluded that DOX had toxic effects on the liver of rats, with significant improvement after treatment with QCT as an antioxidant substance, and that high doses of QCT were more protective than low doses. QCT may be beneficial in DOX administration for increasing its therapeutic efficacy against liver cancer.

\section{References}

Ahmed A, Satyam S, Shetty P and et al., (2020): Methyl gallate attenuates doxorubicin-induced cardiotoxicity in rats by suppressing oxidative stress. Scientifica; Volume 20(21): 1-12.
Ali A, Zaitone S and Moustafa, Y (2015): Boswellic acids synergize antitumor activity and protect against the cardiotoxicity of doxorubicin in mice bearing Ehrlich's carcinoma, Canadian Journal of Physiology and Pharmacology; vol. 93(8): 695-708.

AL-Mosaibih MA (2013): Effects of monosodium glutamate and acrylamide on the liver tissue of adult Wistar rats. Life Science Journal; 10(2): 3542.

Alshabanah OA, Hafez MM, Al-Harbi MM and et al., (2010): Doxorubicin toxicity can be ameliorated during antioxidant L-carnitine sup. The histopathological examination of liver specimens revealed parenchymal necrosis, proliferation of biliary duct in DOX group; lementation. Oxid. Med. Cell Longev; 3: 428-433.

Arzu S, Sava G, Okay S and et al., (2004): Effects of vitamin $\mathrm{E}$ supplementation on oxidative stress in steptozotocin induced diabetic rats. Yonsei Medical Journal; 45: 703-710.

Bancroft JD and Gamble M (2002): Theory and practice of histological techniques. $5^{\text {th }}$ ed London Churchill Livingstone: 172-175.

Barakat BA, Ahmed HA, Bahr H and et al., (2018): Protective Effect of Boswellic Acids against Doxorubicin-Induced Hepatotoxicity: Impact on Nrf2/HO-1 Defense Pathway. Oxidative Medicine and Cellular Longevity; Volume 2018, Article ID 8296451, 1-10.

Beshay NM, Zordoky AA, Mohamed ME and et al., (2011): Acute doxorubicin toxicity differentially alters cytochrome $\mathrm{P} 450$ expression and arachidonic acid metabolism in rat kidney and liver. The American society for pharmacology and experimental therapeutics; 39: 1440-1450.

Beutler E, Duron O and Kelly BM (1963): Improved method for the determination of blood glutathione. J Lab Clin Med. 61: pp. 882-888.

Bulucu F, Ocal R, Karadurmus N and et al., (2009): Effects of $\mathrm{N}$-acetylcysteine, deferoxamine and selenium on doxorubicin-induced hepatotoxicity. Biol. Trace Elem. Res.; 132: pp.184-196.

Chao CL, Hou YC, Chao PD and et al., (2009): The antioxidant effects of quercetin metabolites on the prevention of high glucose-induced apoptosis of human umbilical vein endothelial cells. $\mathrm{Br} \mathrm{J}$ Nutr; 101; pp.1165-1170.

Dong Y, Wang J, Feng D and et al., (2014): Protective Effect of Quercetin against Oxidative Stress and Brain Edema in an Experimental Rat Model of Subarachnoid Hemorrhage. Int. J. Med. Sci. 11: 282-290.

El-Bana E and Kamal M (2019): Protective and Therapeutic Effects of Quercetin on Methotrexate Induced Hepatotoxicity in Adult Albino Rats: Biochemical, Histological and Immunohistochemical Study. EJH.; 43(1): 220-227.

El-Beshbishy HA, Aly AA and El-Shafey M (2012): Lipoic acid mitigates bisphenol A-induced testicular mitochondrial toxicity in rats. Toxicology and Industrial Health; 29(10): 875-887. 
El-Sayyad HI, Al-Haggar MM, El-Ghawet A and et al., (2014): Effect of maternal diabetes and hypercholesterolemia on fatal liver of albino Wistar rats. J. Nut.; 30(3): 326-336.

Etim OE, Farombi EO, Usoh IF and et al., (2006): The protective effect of aloe vera juice on lindane induced hepatotoxicity and genotoxicity. Pakistan Journal of Pharmaceutical Sciences; 19(4): 337-340.

Fernandez-Bortan R, Gorantla V, Sun Xet and et al., (2002): Targeting of glycosaminoglycan-cytokine interactions as a novel therapeutic approach in allotransplantation 1. Transplantation. 74(5): 623629.

Gupta C, Vikram A, Tripathi D, Ramarao et al., (2010): Antioxidant and antimutagenic effect of quercetin against DEN induced hepatotoxicity in rat. Phytotherapy research; 24(1): 119-128.

Guzy J, Kusnir J, Marekova M and et al., (2003): Effect of quercetin on daunorubicininduced heart mitochondria changes in rats. Physiol Res; (6): 773-780.

Hajra S, Patra AR, Basu A and et al., (2018): Prevention of doxorubicin (DOX)-induced genotoxicity and cardiotoxicity: effect of plant derived small molecule indole-3- carbinol (I3C) on oxidative stress and inflammation," Biomedicine \& Pharmacotherapy, 101(4): 228-243.

Hiromasa O, Takahiro T, Sanae, MM and et al., (2005): Induction of reactive oxygen species by bisphenol-A and abrogation of bisphenol Ainduced cell injury by DJ-1. Toxicological Science; 88 (1): 114-126.

Jambhulkar S, Deshireddy S, Babu D and et al., (2014): Quercetin Attenuating Doxorubicin Induced Hepatic, Cardiac and Renal Toxicity in Male Albino Wistar Rats. American Journal of Phytomedicine and Clinical Therapeutics, AJPCT; 2(8): 985-1004.

Kei S, (1978): Serum lipid peroxide in cerebrovascular disorders determined by a new colorimetric method. Clinica Chimica Acta. 90(1): 37-43.

Kim BM, Choi YJ and Han Y (2009): N,N-dimethyl phytosphingosine induces caspase-8-dependent cytochrome c release and apoptosis through ROS generation in human leukemia cells. Toxicol. Appl. Pharmacol; 239: 87-97.

Lirdi LC, Stumpp T, Sasso-Cerri E and et al., (2008): Amifostine protective effect on cisplatin-treated rat testis. Anatomical Record; 291: 797-808.

Mete E, Oran M, Topcu B et al., (2016): Protective effects of onion (Allium cepa) extract against doxorubicin-induced hepatotoxicity in rats. Toxicology and Industrial Health, Vol. 32(3): 551-557.

Milic VD, Stankov K, Injac R and et al., (2009): Activity of antioxidative enzymes in erythrocytes after a single dose administration of doxorubicin in rats pretreated with fullerenol C60(OH)24. Toxicol Mech Methods; 1: pp. 2428.
Moskaug JO, Carlsen H, Myhrstad M and et al., (2004): Molecular imaging of the biological effects of quercetin and quercetin-rich foods. Mech. Ageing Dev.; 125(4): 315-324.

Odbayar TO, Kimura T, Tsushida T and et al., (2009): Isoenzyme-specific upregulation of glutathione transferase and aldo-keto reductase mRNA expression by dietary quercetin in rat liver. 325(2): 121-130.

Pandit A, Sachdeva T, and Bafna P (2012): Druginduced hepatotoxicity: a review. Journal of Applied Pharmaceutical Science; 2(5): 233243.

Poole A, Herwijnen P, Weideli $\mathrm{H}$ and et al., (2004): Review of the toxicology, human exposure and safety assessment for bisphenol A diglycidylether (BADGE), Food Additives and Contaminants; 21(9): 905-919.

Qader GI, Aziz RS, Ahmed ZA and et al., (2014): Protective Effects of Quercetin against Isoniazid and Rifampicin Induced Hepatotoxicity in Rats. Am. J. Pharmacol. Sci. 2, 56-60

Reitman S and Frankel SA (1957): Colorimetric method for the determination of serum glutamic pyruvate and glutamic oxaloacetate transaminase. Amer J Clin. Path.: 28(56).

Reutrakul C, Ningnuek N, Pohmakotr $\mathrm{M}$ and et al., (2007): Planta Med. 73, 683.

Richter CA, Birnbaum LN, Farabollini F and et al., (2007): In vivo effects of bisphenol $A$ in laboratory rodent studies. Reproduction Toxicology; 24: 199-224.

Shehab NG, Abu-Gharbieh E and Bayoumi FA (2015): Impact of phenolic composition on hepatoprotective and antioxidant effects of four desert medicinal plants. BMC Complement Altern. Med.; 15: 401.

Shi C, Zhao L, Zhu B and et al., (2009): Protective effects of Ginkgo biloba extract (EGb761) and its constituent quercetin and ginkgolide $\mathrm{B}$ against $\beta$ amyloid peptide-induced toxicity in SH-SY5Y cells. Chem Biol Interact; 181: 115-123.

Suematsu N, Hosoda M and Fujimori K (2011): Protective effects of quercetin against hydrogen peroxide-induced apoptosis in human neuronal SH-SY5Y cells. Neurosci Lett 504: 223-227.

Tiong KH, Yiap BC, Tan EL and et al., (2010): In vitro modulation of naturally occurring flavonoids on cytochrome P450 2A6 (CYP2A6) activity. Xenobiotica; 40: 458-66.

Verma RJ and Sangai NP (2009): The ameliorative effect of black tea extract and quercetin on bisphenol A-induced cytotoxicity. Acta. Pol. Pharm. Drug Res.; 66: pp. 45-50.

Verstraeten SV, Frag CG and Oteiza, PI (2015): Interactions of flavan-3-ols and procyanidins with membranes: Mechanisms and the physiological relevance. Food Funct. (6): 32-40.

Wang G, Zhang Z, Liu L and et al., (2012): Quercetin Potentiates Doxorubicin Mediated Antitumor Effects against Liver Cancer through p53/Bclxl. 7 (12):1-12. 
Zordoky BN, Anwar MA, Aboutabl ME et al., (2011):

Acute Dox Toxicity Differentially Alters

Cytochrome P450 Expression and Arachidonic

Acid Metabolism in Rat Kidney and Liver.

Drug Metab. Dispos. (39):1440-1450.

\title{
التأثير المحتمل للحماية بالكورستين ضد السمية الكباية الناجمة عن الدوكسوروبيسين في ذكور الجرذان

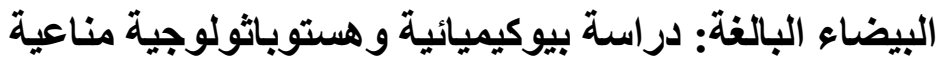

\author{
سحر محمد مصطفى' منى حسن على
}

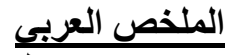

المقدمة: يعتبر الدوكسوروبيسين مضاداء للأورام ولكنه يسبب تسمم الكبد من خلال توليد الجذور الحرة بالإضافة إلى الضرر

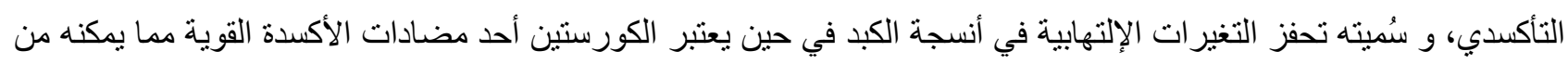

تخفيف السمية الكبدية.

الههف من البحث: الكثف عن التأثير السمي للاوكسوروبيسين على أنسجة الكبد وتقييم الدور الوقائي المحتمل للكورستين ضد ضد الكيد التغير ات السمية التى قد يسبيها الدوكسوروبيسين في كبد ذكور الجرذان البيضاء البالغة.

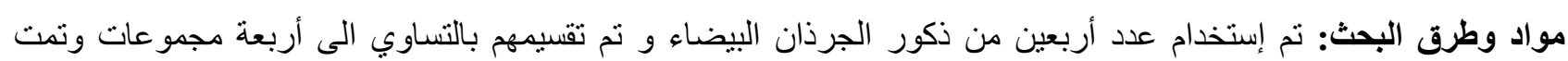
معالجتهم على النحو التالي: المجموعة الأولى: المجموعة الضابطة، المجموعة الثمن الثانية المعالجة بالدوكسوروبيسين: حيث تلقت

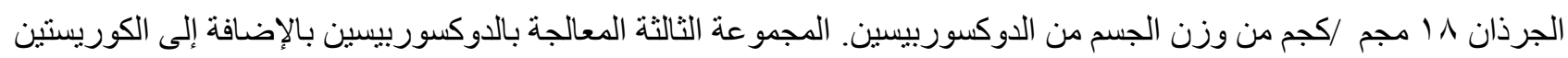

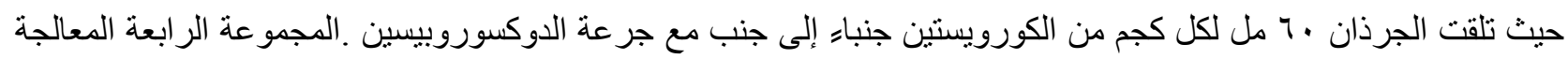

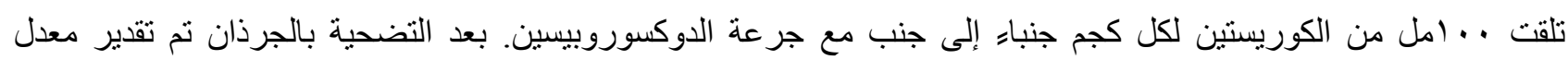

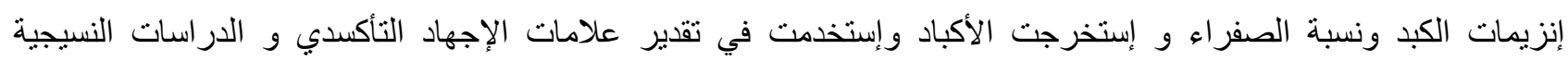

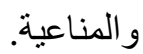
النتائج: نتج عن إعطاء الدوكسوروبيسين إلى الجرذان البيضاء زيادة ملحوظة في إنزيمات الكبد و نسبة الصفراء و علامات

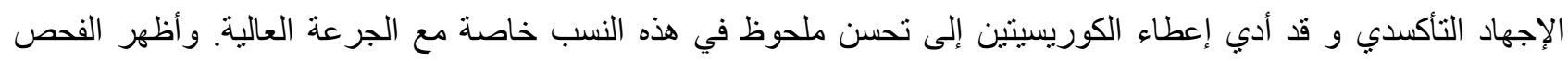

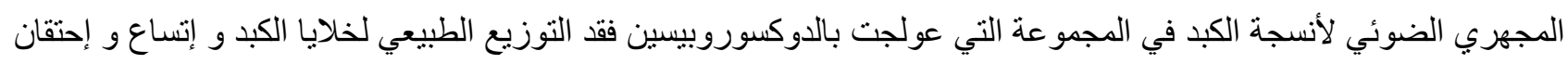

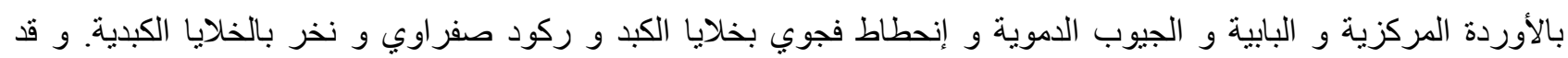

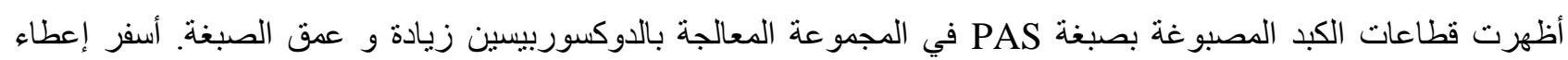

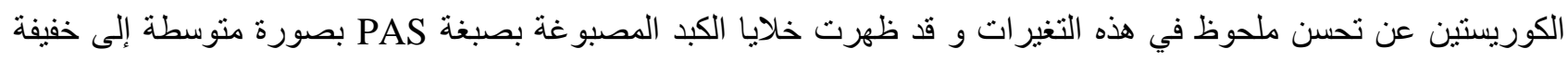

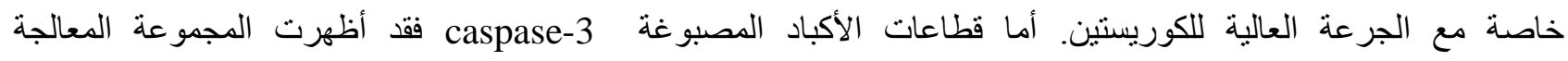

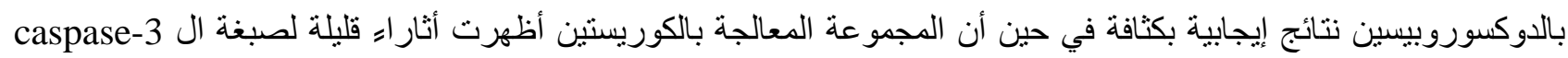
خاصة مع الجر عة العالية. الخلاصة: خلصت هذه الدراسة إلى أن الدوكسوروبيسين له آثار سمية على كبد الجرذان البيضاء مع حدوث تحسن ملحوظ بعد

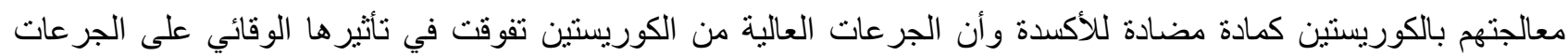

